\section{Electric Fields, Cloud Microphysics, and Reflectivity in Anvils of Florida Thunderstorms}

\author{
J.E. Dye
}

National Center for Atmospheric Research, Boulder CO

M.G. Bateman

Universities Space Research Association, Huntsville AL

H.J. Christian

Univ. of Alabama in Huntsville, Huntsville AL

E. Defer

Observatoire de Paris, Paris, France

C.A. Grainger

Univ. of North Dakota, Grand Forks ND

W.D. Hall

National Center for Atmospheric Research, Boulder CO

E.P. Krider

Univ. of Arizona, Tucson AZ

S.A. Lewis

NOAA/Univ. of Colorado, Coop. Inst. for Research in Environmental Sciences, Boulder CO

D.M. Mach

Univ. of Alabama in Huntsville, Huntsville AL

F.J. Merceret

National Aeronautics and Space Administration, Kennedy Space Center FL

J.C. Willett

Garrett Park MD

P.T. Willis

NOAA Cooperative Institute for Marine and Atmospheric Sciences; Miami FL

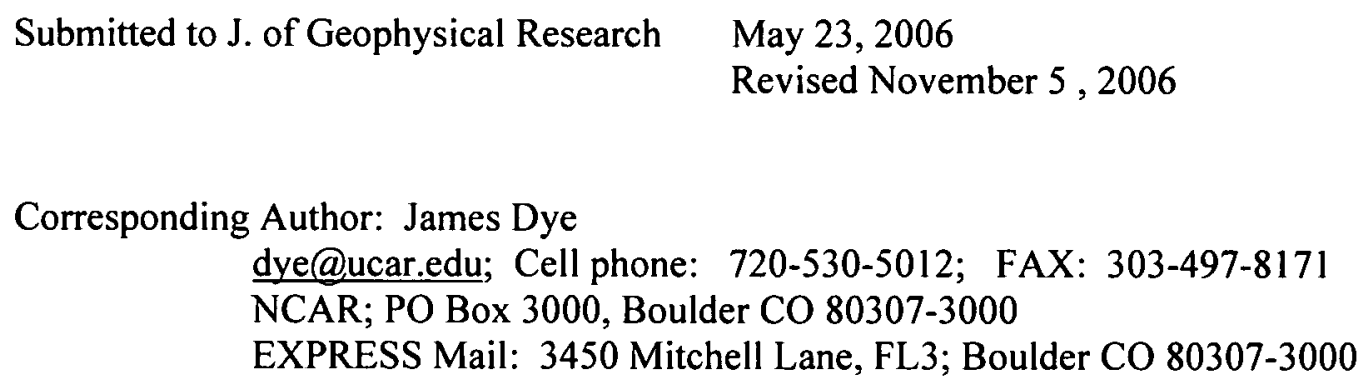

Submitted to J. of Geophysical Research May 23, 2006

Revised November 5, 2006

Corresponding Author: James Dye

dye@ucar.edu; Cell phone: 720-530-5012; FAX: 303-497-8171

NCAR; PO Box 3000, Boulder CO 80307-3000

EXPRESS Mail: 3450 Mitchell Lane, FL3; Boulder CO 80307-3000 


\section{ABSTRACT}

A coordinated aircraft - radar project that investigated the electric fields, cloud microphysics and radar reflectivity of thunderstorm anvils near Kennedy Space Center is described. Measurements from two cases illustrate the extensive nature of the microphysics and electric field observations. As the aircraft flew from the edges of anvils into the interior, electric fields very frequently increased abruptly from $\sim 1$ to $>10 \mathrm{kV} \mathrm{m}^{-1}$ even though the particle concentrations and radar reflectivity increased smoothly. The abrupt increase in field usually occurred when the aircraft entered regions with a reflectivity of 10 to $15 \mathrm{dBZ}$. It is suggested that the abrupt increase in electric field may be because the charge advection from the storm core did not occur across the entire breadth of the anvil and was not constant in time. Screening layers were not detected near the edges of the anvils. Some long-lived anvils showed subsequent enhancement of electric field and reflectivity and growth of particles, which if localized, might be a factor in explaining the abrupt change of field in some cases.

Comparisons of electric field magnitude with particle concentration or reflectivity for a combined data set that included all anvil measurements showed a threshold behavior. When the average reflectivity, such as in a 3-km cube, was less than approximately $5 \mathrm{dBZ}$, the electric field magnitude was $<3 \mathrm{kV} \mathrm{m} \mathrm{m}^{-1}$. Based on these findings, the Volume Averaged Height Integrated Radar Reflectivity (VAHIRR) is now being used by NASA, the Air Force and Federal Aviation Administration in new Lightning Launch Commit Criteria as a diagnostic for high electric fields in anvils. 
1. Introduction

Numerous studies have been conducted to examine the microphysical conditions and radar reflectivity structure of convective clouds when charge separation is beginning and electric fields are intensifying, but few studies have examined the decay of electric fields in space and/or time in thunderstorm anvils as a function of the cloud microphysics and radar reflectivity. Since thunderstorm anvils can contain high electric fields, they pose a significant threat for triggering lightning during space flight operations. Until recently the mission launch rules at the National Aeronautics and Space Administration (NASA) Kennedy Space Center (KSC) and the Air Force Eastern Range would prevent a space vehicle from flying through non-transparent anvils or even an anvil detached from the parent convection if lightning had occurred within the last 3 hours in the parent storm or the anvil [Krider et. al., 1999].

The Airborne Field Mill II experiment (ABFM II) was conducted near KSC to measure the electric field, reflectivity and microphysics in thunderstorm anvils (and other clouds) produced by deep convection with the hope that the launch constraints involving anvil clouds could be safely relaxed. In this paper we present a brief overview of the ABFM II campaigns, examples of some of the measurements, and a synthesis of the results obtained in 14 different flights through anvils. During the analysis of ABFM II observations and while attempting to compare the observations with estimates of electric field decay predicted from a simple model [Willett and Dye, 2003], we found that reflectivity and strong electric fields persisted and became uniform in a stratiform-like mid-level layer for many tens of minutes over many tens of kilometers well downstream of the parent convection. This "enhancement" of reflectivity, electric field and 
95 microphysics in two long-lived anvils is discussed in a separate paper [Dye and Willett,

962006 ] that argues that weak updrafts were probably present and that charge separation

97 must have occurred in these long-lived anvils. The simple model based on ABFM II

98 particle observations, which was used to estimate the electric field decay in passive anvils

99 and compared with the electric field observations from ABFM II, will be described

100 elsewhere.

101

102 2. The Airborne Field Mill Experiment

103 The ABFM II campaigns were conducted during June 2000 and May-June 2001 to

104 investigate the relationships between microphysics, radar reflectivity and the decay of

105 electric fields (both spatially and temporally) in thunderstorm anvils and other clouds. In-

106 situ measurements of the 3-D electric field; particle concentration, types and sizes; and

107 standard thermodynamic and flight measurements were made using a Citation II jet

108 aircraft operated by the University of North Dakota (UND). [See Ward et al., 2003, for

109 information on the Citation and its instrumentation for ABFM II.] The aircraft

110 measurements were coordinated with reflectivity measurements by the WSR-74C radar at

111 Patrick Air Force Base, FL and the NEXRAD WSR-88D radar at Melbourne, FL. The

112 occurrence and location of intra-cloud (IC) and cloud-to-ground (CG) lightning flashes

113 were determined using the KSC Lightning Detection and Ranging (LDAR) system

114 [Lennon and Maier, 1991] and the KSC Cloud to Ground Lightning Surveillance System

115 (CGLSS) [Maier, 1991].

116 The anvils ranged in size from small anvils of short-lived airmass thunderstorms to

117 anvils formed by mid-level outflow to large anvils of intense multi-cellular, long-lived 
118 thunderstorms. Initial penetrations were often made across the anvil outflow close to the

119 convective cores of the storms. Subsequent cross anvil passes were made at different

120 distances downstream to examine the decay of the electric field both with time and

121 distance. Some passes were also made along the axis of the anvil outflow either towards 122 or away from the core of the storm.

123 Aircraft penetrations were typically made at altitudes ranging from 7 to $11 \mathrm{~km} \mathrm{MSL}$

$124[-15$ to $-45 \mathrm{C}]$, with $80 \%$ of the penetrations made at 8 to $10 \mathrm{~km} \mathrm{MSL}$ (about -20 to -35

$\left.125{ }^{\circ} \mathrm{C}\right)$ and mostly near $9 \mathrm{~km} \mathrm{MSL}\left(\sim-31\right.$ to $\left.-32{ }^{\circ} \mathrm{C}\right)$, because the middle of the anvil was

126 usually at these altitudes. (Hereafter all altitudes are referenced to mean sea level, MSL).

127 Spiral ascents or descents were made through the anvils when Air Traffic Control (ATC)

128 would allow, but these were relatively infrequent due to heavy airliner traffic in that

129 region of Florida. In some cases the aircraft arrived after most of the electric field had

130 already decayed but these cases are also useful because we know the reflectivity history

131 of these storms and the time of the last lightning relative to the aircraft penetrations.

132 Decisions on where to fly were based on interactions between the air crew and ground

133 coordinators at the Air Force Range Operations Control Center (ROCC), where aircraft

134 track could be overlaid on vertical and horizontal cross-sections of the radar reflectivity

135 and where displays of lightning, ground-based electric field, and satellite observations

136 were available in real time.

137 In the following sub-sections we present a brief summary of instruments and

138 measurement systems used during the project. More information on each of these

139 measurement systems can be found in Dye et al. [2004].

140 
142 The 3-dimensional electric field was measured in situ from the UND Citation using

1436 low noise, high dynamic range, rotating-vane field mills that were designed and built at

144 NASA Marshall Space Flight Center [Bateman et al., 2006]. The use of two input 145 channels with overlapping gains and 16 bit analog-to-digital converters permitted a 146 measurement range from less than $1 \mathrm{~V} / \mathrm{m}$ to $150 \mathrm{kV} \mathrm{m}^{-1}$. The data were digitized inside 147 each field mill close to the source so as to minimize electrical noise from the aircraft. The 148 mills were time synchronized to within $16 \mathrm{~ms}$ of each other by a central data collection 149 computer for the field mills and the overall timing accuracy was within $50 \mathrm{~ms}$ of UTC.

150 The data were recorded at 50 samples $\mathrm{s}^{-1}$ but for this paper were averaged and plotted at 1 151 sample $\mathrm{s}^{-1}$.

152 When the aircraft was out of cloud, the charge on the aircraft was usually very 153 small. Based on the analysis of Mach and Koshak [2003] we feel that the uncertainty in 154 the measured electric field out of cloud was within $+/-10 \%$. When the aircraft penetrated 155 a cloud, however, the errors increased significantly due to aircraft charging. In this case,

$156 E_{z}$ and $E_{y}$, the field components in the vertical and along the wings, respectively, were 157 accurate to about $20 \%$. The $\mathrm{E}_{\mathrm{x}}$ component along the fuselage was much less accurate. 158 (We used a right-handed coordinate system with $E_{z}$ positive upward, $E_{x}$ positive forward 159 and a sign convention in the traditional physics sense, i.e. a positive field shows the 160 direction in which a positive charge would move. $E_{x}, E_{y}$ and $E_{z}$ are relative to the 161 aircraft.) More details on the placement of the field mills on the aircraft, the techniques 162 used to determine the 3-dimensional electric field and calibration of the system can be 163 found in Mach and Koshak [2003] and in Appendix B of Dye et al., [2004]. 
1652.2 Airborne Microphysical Measurements

166 Five separate microphysical instruments were flown on the Citation to determine

167 the concentration, sizes, and types of particles ranging from a few microns to about 5

168 centimeters, thus covering a range from frozen cloud droplets to large aggregates.

169 Descriptions of all instruments used are available in the literature. Herein we cite only

170 recent publications that discuss the measurement techniques, sources of measurement

171 error and that include references to earlier published studies of that instrument. A Particle

172 Measuring Systems (PMS) Forward Scattering Spectrometer Probe (FSSP) was used for

173 the size range of a few microns to $\sim 50 \mu \mathrm{m}$. The FSSP was designed to measure water

174 droplets and has shortcomings in ice and mixed phase clouds [Field et al., 2004]. We

175 used the FSSP only as an indication of the relative concentration of the small ice

176 particles. A PMS 2D Cloud probe (2D-C) [Strapp et al., 2001; Field et al., 2006]

177 nominally covered the range of $30 \mu \mathrm{m}$ to a few millimeters and gave shadow images of

178 the particles from which information on particle type can be obtained as well as the size

179 and concentration. A PMS 1D cloud probe (1D-C), which is similar to the 2D-C but does

180 not image the particles, gave measurements of the concentration of particles in 15 size

181 bins from 15 to $960 \mu \mathrm{m}$. A Stratton Park Engineering Corp (SPEC) Cloud Particle Imager

182 (CPI) [Lawson et al., 2001] provided images of particles with resolution of $2.5 \mu \mathrm{m}$ over

183 its effective size range of $\sim 10 \mu \mathrm{m}$ to about $1 \mathrm{~mm}$, with images of the larger sizes limited

184 by the small sample volume. Measurements from the CPI were used only to examine

185 particle type. The SPEC High Volume Particle Sensor (HVPS) [Lawson et al., 1998]

186 images particles in the nominal range of $1 \mathrm{~mm}$ to $5 \mathrm{~cm}$ with a resolution of $400 \mu \mathrm{m}$ along 
187 the direction of flight and $200 \mu \mathrm{m}$ in the cross stream direction. Like the 2D-C, special 188 software is needed to process the data and determine concentration in different size 189 ranges. We used software developed at NCAR for processing and displaying the ABFM

190 II microphysical measurements. In general the cloud physics instruments worked well

191 and normally there was very good agreement in the overlap regions between different 192 probes.

193 Assigning an uncertainty to the concentration and size measurements from each 194 instrument is not straightforward. The concentration, $n_{i}$, in any size interval, $i$, measured 195 by these instruments is $C_{i} / v_{i}$, where $C_{i}$ and $v_{i}$ are the number of counts and sample 196 volume in that size interval. The statistical uncertainty of the measured concentration in 197 that size bin is then approximately $\left({ } C_{i}\right) / v_{i}$. The number of counts in the size bins of each 198 instrument is dependent upon the integration time and the relative abundance of particles. 199 In ABFM II for $10 \mathrm{~s}$ averaging periods, in the small/intermediate-sized intervals we 200 typically counted many tens or hundreds of particles, whereas for the larger size bins of 201 each instrument the number of counts was typically only a few particles. Thus there is 202 little statistical uncertainty $(<10 \%)$ for the small to mid size range measured by each 203 instrument and a factor of 2 or more uncertainty for the largest sizes. Because of the 204 overlap between the 2D-C and the HVPS for the millimeter-sized particles, the statistical 205 uncertainty of the composite size distributions in this overlap region is probably $<30 \%$, 206 when both instruments are functioning well. Errors in sizing for these instruments are 207 greatest when the particle size becomes comparable to the spacing between the diode 208 elements [See Strapp et al., 2001] and when the particles are larger than or near the size 209 of the full width of the diode array. For the 2D-C flown on the Citation this width is 
210 roughly $1 \mathrm{~mm}$. In the middle of the size range of each instrument, sizing errors are 211 probably $<15 \%$.

212 In addition to the particle probes the Citation carried a King liquid water sensor and 213 a Rosemount Icing Detector [Heymsfield and Miloshevich, 1989]. The measurements

214 from the King liquid water sensor were rarely used in our ABFM II analyses because we

215 flew mostly in anvils and other cloud regions that contained primarily ice particles. The

216 Icing Detector was a valuable instrument that allowed us to determine when supercooled

217 liquid water was present in our clouds. Analysis of the icing detector measurements by

218 Schild [2003] and other unpublished undergraduate work at UND showed no evidence of

219 supercooled water in the ABFM II anvils, so all particles discussed in this paper are

220 considered to be ice.

221

$222 \quad 2.3$ Radar Reflectivity Measurements

223 Radar measurements were obtained from a WSR-74C (74C) radar located at Patrick

224 Air Force Base (about $25 \mathrm{~km}$ south of KSC) and the WSR-88D (88D) NEXRAD radar

225 located at Melbourne, Florida about $18 \mathrm{~km}$ to the southwest of the $74 \mathrm{C}$ radar. (The

226 location of the $74 \mathrm{C}$ radar was used as the origin in all of our radar plots). The $74 \mathrm{C}$ radar

227 provides support for all launch operations at KSC and the Air Force Eastern Range. The

$22874 \mathrm{C}$ is a C-band $(5.3 \mathrm{~cm})$, horizontally polarized weather radar without Doppler

229 capability. The peak power was $250 \mathrm{~kW}$ with a pulse repetition frequency (PRF) of 160

$230 \mathrm{~Hz}$. The beam width was 1.05 degrees and the pulse width was $4 \mu \mathrm{s}$. It had a maximum

231 range of $256 \mathrm{~km}$ with a range resolution of $250 \mathrm{~m}$. Measurements were made during 
232 antenna ascent and descent with twelve interleaved 360 degree sweeps. A complete

233 volume scan was made every $2.5 \mathrm{~min}$.

234 The NEXRAD 88D is an S-band $10 \mathrm{~cm}$ circularly polarized, Doppler weather radar.

235 The beam width was 0.95 degrees; the pulse width was 1.57 or $4.7 \mu$ s; and peak power

236 was $750 \mathrm{~kW}$. The PRF varied from 318 to $1304 \mathrm{~Hz}$. Pulse pair processing was used to

237 recover the Doppler information. The normal range was $230 \mathrm{~km}$, but degraded reflectivity

238 data could be obtained at ranges as far as $460 \mathrm{~km}$. A complete volume scan took 5 to 6

239 min. All ABFM II measurements were from the Volume Coverage Pattern precipitation-

240 mode scan strategy, VCP 11 [OFCM, 2003].

241 The universal format data from both radars were converted to a Cartesian $1 \mathrm{~km}$ grid

242 with $1 \mathrm{~km}$ horizontal and vertical spacing over a 225 by $225 \mathrm{~km}$ domain using SPRINT

243 [Mohr et al., 1986]. SPRINT was configured to perform a bi-linear interpolation with a

244 maximum acceptable distance of $0.2 \mathrm{~km}$ to relocate a closest point estimate and with no

245 range interpolation. The reflectivity was converted from $\mathrm{dB}$ to a linear scale for

246 interpolation. Subjective comparisons of horizontal and vertical cross-sections of the 74C

247 and $88 \mathrm{D}$ data sets showed good agreement when attenuation of the $74 \mathrm{C}$ was not a factor.

248 Additionally, statistical tests were done for a limited set of quantitative reflectivity

249 comparisons and found that the systematic differences (without attenuation) were less

250 than $1 \mathrm{dBZ}$ when examined over volumes of several tens of $\mathrm{km}^{3}$.

251 Attenuation of the $74 \mathrm{C}$ measured reflectivity was apparent behind regions of heavy

252 precipitation or when the radome of the $74 \mathrm{C}$ was wetted due to precipitation. The $74 \mathrm{C}$

253 observations were manually checked for each flight to determine times when attenuation

254 had occurred. For the analyses presented in Section 4 below NEXRAD data were 
255 substituted for the $74 \mathrm{C}$ data when $74 \mathrm{C}$ attenuation occurred for an individual case. Both

256 radars have a cone of silence directly above the radar that was not scanned because it lies

257 at an elevation angle higher than the elevation of the highest sweep angle. At an anvil

258 altitude of $9 \mathrm{~km}$, this corresponded to a horizontal diameter of $\sim 20 \mathrm{~km}$ for the $74 \mathrm{C}$ and

$259 \sim 30 \mathrm{~km}$ for the 88D radars. The airborne data set which is used in Section 4 were

260 carefully edited so that it did not include data points when the anvil was in the cone of

261 silence of the appropriate radar.

262 When the difference between adjacent elevation sweeps exceeded the beam width

263 of that radar, scan gaps occurred, i.e. the radar did not completely sample the entire

264 volume of radar space. These gaps produced a ragged appearance of the anvil tops, bases

265 and sides in the cross sectional displays of the reflectivity measurements, particularly for

266 storms far from the radar. The effects of radar propagation can also cause the actual

267 altitude to differ from the indicated altitude by a couple of kilometers [Wheeler, 1997].

268 These issues could present a problem when trying to compare the airborne measurements

269 with the radar reflectivity measurements from the $1 \times 1 \times 1 \mathrm{~km}$ gridded data.. Some of the

270 grid points can be in a scan gap and there can also be propagation effects. Constant

271 Altitude Plan Position Indicator (CAPPI) plots and vertical sections along the aircraft

272 tracks that are presented in this paper were based on the 1-km gridded radar data, so they

273 sometimes display the artifacts. However, when airborne measurements of electric field

274 or particle concentrations are plotted versus the radar reflectivity in Section 4 below, the

$2751 \mathrm{~km}$ gridded reflectivity data were averaged in $\mathrm{dBZ}$ over a $3-\mathrm{km}$ cube in order to

276 mitigate the effects of scan gaps and propagation effects. Pixels with no detectable return 
were not included in the averages and we required that 16 of the 27 pixels in a $3-\mathrm{km}$ cube contain measurable reflectivity.

\subsection{Lightning Measurements}

Two lightning detection systems were used during ABFM II to determine

282 occurrence, location, and frequency of lightning discharges. The Lightning Detection 'and

283 Ranging (LDAR) system, which is a total lightning system using time-of-arrival

284 techniques, located the sources of VHF radiation from lightning from 63 to $69 \mathrm{MHz}$

285 [Lennon and Maier, 1991]. It consisted of a central site and 6 remote sensors that were

286 approximately $10 \mathrm{~km}$ radius from the central site. Studies by Boccippio et al., [2000a and

287 b] show that the flash detection efficiency is $>90 \%$ within $100 \mathrm{~km}$ range and $<25 \%$ at 200

$288 \mathrm{~km}$ range. The VHF source location error distribution is a function of range with a mean

289 horizontal error of about $200 \mathrm{~m}$ at $100 \mathrm{~km}$. [See Figure 3 in Boccippio 2000b]. For most

290 of our analyses we plotted the individual VHF sources overlaid on radar CAPPIs to show

291 when and where lightning discharges occurred and have not separated the sources into

292 flashes.

293 The Cloud to Ground Lightning Surveillance System (CGLSS) provided the

294 locations and times of cloud-to-ground (CG) return strokes [Maier, 1991]. During ABFM

295 II this system used 6 Global Atmospherics Inc. 141-T Advanced Lightning Direction-

296 Finders operating over a wide bandwidth in and below the MF, an IMPACT 280-T

297 Advanced Position Analyzer employing both radio-direction-finding and time-of-arrival

298 techniques, and associated displays. The system was similar to the National Lightning

299 Detection Network [Cummins et al., 1998]. The sensors extended approximately $40 \mathrm{~km}$ 
300 to the north, west and south of KSC. Within the perimeter of the network the accuracy of

301 location of CG strokes was about $300 \mathrm{~m}$ [Boyd et al., 2005]. At a range of $100 \mathrm{~km}$ from

302 the network the accuracy degraded to roughly $3 \mathrm{~km}$. When all six sensors were

303 functioning properly the detection efficiency was better than $98 \%$. More information on

304 LDAR and CGLSS use in ABFM II can be found in Appendices F and G of Dye et al., 305 [2004].

306

307 3. Examples from Two Storms

308 One of our first observations during ABFM II was that the transition from weak

309 electric fields $\left(\sim 1 \mathrm{kV} \mathrm{m}^{-1}\right)$ to thunderstorm strength fields $\left(\sim 10 \mathrm{kV} \mathrm{m}^{-1}\right)$ in anvils was

310 usually quite abrupt, and it occurred when the Citation flew from regions that had a

311 reflectivity $<10 \mathrm{dBZ}$ into regions with greater reflectivity. Analysis also showed that the

312 transition to strong fields was quite rapid in comparison to the more smoothly varying

313 particle concentrations in all size ranges and radar reflectivity. Based on this finding by

314 June 2001 the ground coordinators could often tell the aircraft crew where to expect large

315 increases/decreases in electric fields based on the reflectivity display. In this section we

316 present two cases that illustrate the kinds and quality of the observations that were made

317 during ABFM II and that also illustrate the abrupt increases in electric field.

$319 \quad 3.113$ June 2000

320 The June 13th storm was a long-lived storm with a well developed anvil that was 321 investigated by the Citation for over 3 hours from 2045 UTC to after 2400 UTC. (UTC is 322 used throughout this paper; subtract four hours for local daylight time.) The Citation first 
323

324

325

326

327

328

329

330

331

332

333

334

335

336

337

338

339

340

341

342

343

344

345

entered the anvil when it was relatively small ( $\sim 40 \mathrm{~km}$ length at $10 \mathrm{~km}$ altitude), but well defined. By 2200 the anvil at $10 \mathrm{~km}$ altitude, as deduced from radar observations, extended more than $100 \mathrm{~km}$ downwind of the original convective core. Penetrations were made from east to west or vice versa at 10 to $11 \mathrm{~km}$ altitude across the anvil at 25 to 50 $\mathrm{km}$ from the storm core from 2050 until 2225. After 2225 penetrations were made along or opposed to the direction of the wind along the axis of the anvil from southwest to northeast until $\sim 0005$, first at $11 \mathrm{~km}$ altitude, then $9 \mathrm{~km}$ and finally $8 \mathrm{~km}$ as the anvil subsided. In a separate paper Dye and Willett [2006] use this case as well as the case of 4 June 2001 to illustrate the enhancement in reflectivity and electric field that was observed in some long-lived anvils. More information on the latter stages of the June $13^{\text {th }}$ storm can be found in that paper.

An example of an early cross anvil penetration from 2103 to 2111 is shown in Figure 1 , as the Citation was climbing from 10 to $11 \mathrm{~km}$. The reflectivity structure in the $10 \mathrm{~km}$ CAPPI reflects the downshear outflow and some upshear divergence from the upper level updraft. The maximum reflectivity in the storm at this time was $55-60,50-$ 55 , and 40 to $45 \mathrm{dBZ}$ at 4,7 and $10 \mathrm{~km}$, respectively but the reflectivity pattern of the core is obscured in Figure 1 by the red triangles showing the CG strokes. The CGLSS system showed that CG lightning occurred in the convective cores from 1915 until 2135. Because the LDAR system was not functioning properly in June 2000 until the following day, there is a paucity and miss-location of LDAR VHF sources in Figure 1.

Comparison of the 10 and $4 \mathrm{~km}$ CAPPIs in Figure 1 shows that the anvil extended more than $50 \mathrm{~km}$ to the north, northeast of the main convection. There was some weak low-level convection north of the main core. The reflectivity curtain in the third panel of 
Figure 2 near 2109 to 2110 shows precipitation falling to the ground in this region. From

3472103 to 2108 the penetration was in the anvil that extended to the east. It is anvils such as

348 this that have a well defined base that are the focus of the studies described herein.

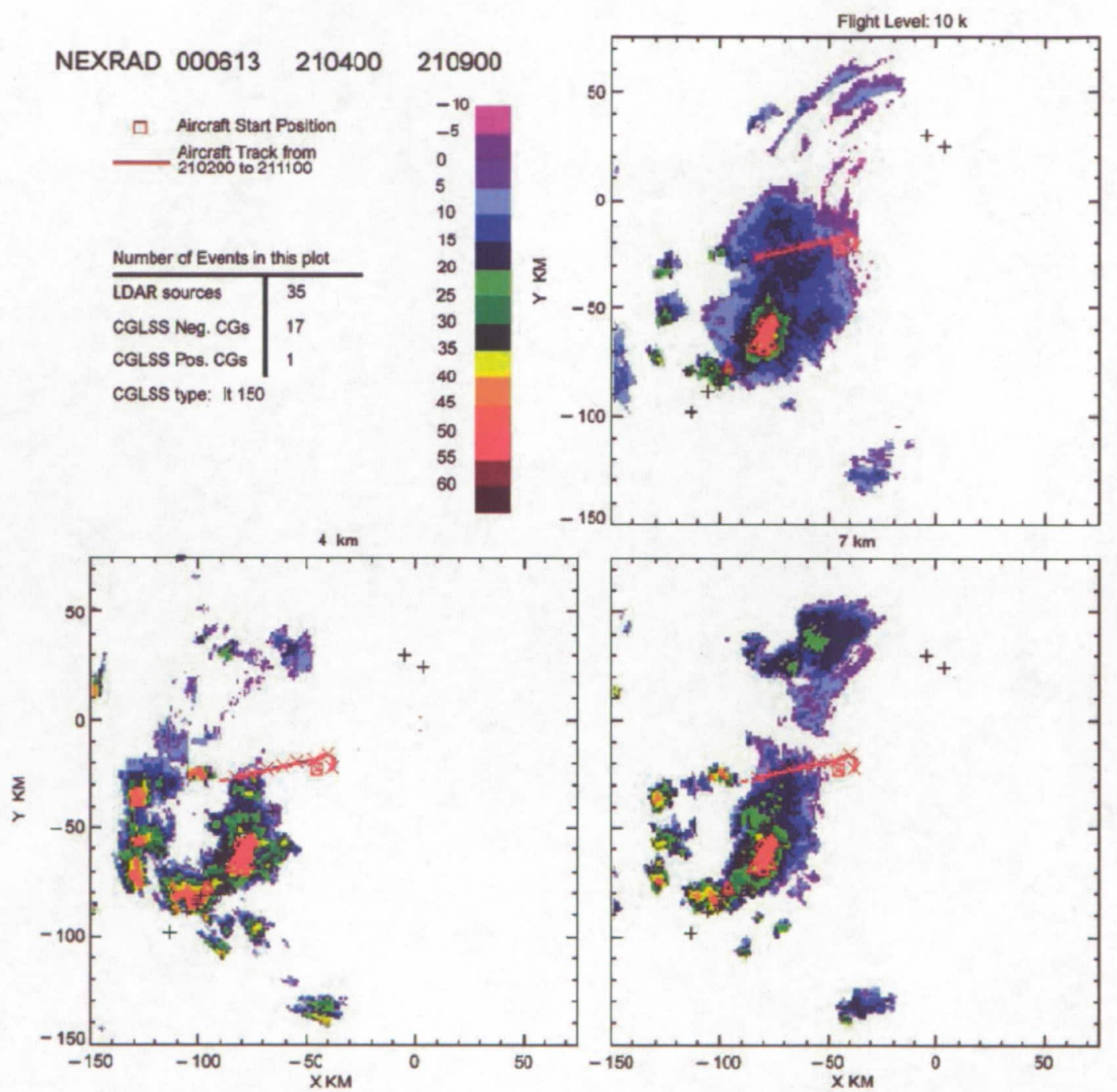

Figure 1 CAPPIs of reflectivity at 4, 7 and $10 \mathrm{~km} \mathrm{MSL}$ for the $2104-2109$ NEXRAD volume scan with the Citation track from 2102 to 2111 overlaid in red. The initial position of the aircraft is shown by a square with Xs showing each successive minute along the track. Red triangles show the positions of CG flashes detected by the CGLSS system during this volume scan. The ground projection of LDAR VHF sources are shown by black pluses. 
359 flight speed of $\sim 120 \mathrm{~m} / \mathrm{s}$, one minute corresponds to roughly $7 \mathrm{~km}$ of horizontal distance.

360 The figure shows a dramatic increase in electric field as the aircraft approached a 361 reflectivity of about $15 \mathrm{dBZ}$ near 2107 . The scalar magnitude of the vector electric field, 362 Emag, (henceforth called the electric field magnitude) bottom panel in figure 2, increased

363 from $\sim 3 \mathrm{kV} \mathrm{m}^{-1}$ to $\sim 20 \mathrm{kV} \mathrm{m}^{-1}$ in about $10 \mathrm{~s}(\sim 1200 \mathrm{~m})$. This large, rapid increase in field 364 was a common feature of the ABFM II measurements. During this penetration the field 365 magnitude was dominated by $E_{z}$. Note that in the MER plots, $E_{z}$ is plotted on a linear 366 scale shown on the left side of the figure, while the field magnitude, Emag, is plotted on a $367 \log$ scale on the right side of the figure. $E_{x}$ and $E_{y}$ contributed somewhat to the field 368 magnitude, but the contributions were small. The dominance of the vertical component of 369 the field was found to be true in almost all of the penetrations even when a penetration of 370 the anvil was made close to the convective core of the storm. Note that the sharp increase 371 in electric field occurs more than $3 \mathrm{~min}(\sim 20 \mathrm{~km})$ after the aircraft entered the anvil and a 372 minute $(\sim 7 \mathrm{~km}$ distance $)$ before the aircraft passed over precipitation that was reaching the 373 ground (Figure 2). The measurements shown in Figure 2 are typical of those from other 374 penetrations, some of which were farther from the core and the low-level convection seen 375 on the west side of the storm in Figure 1. 

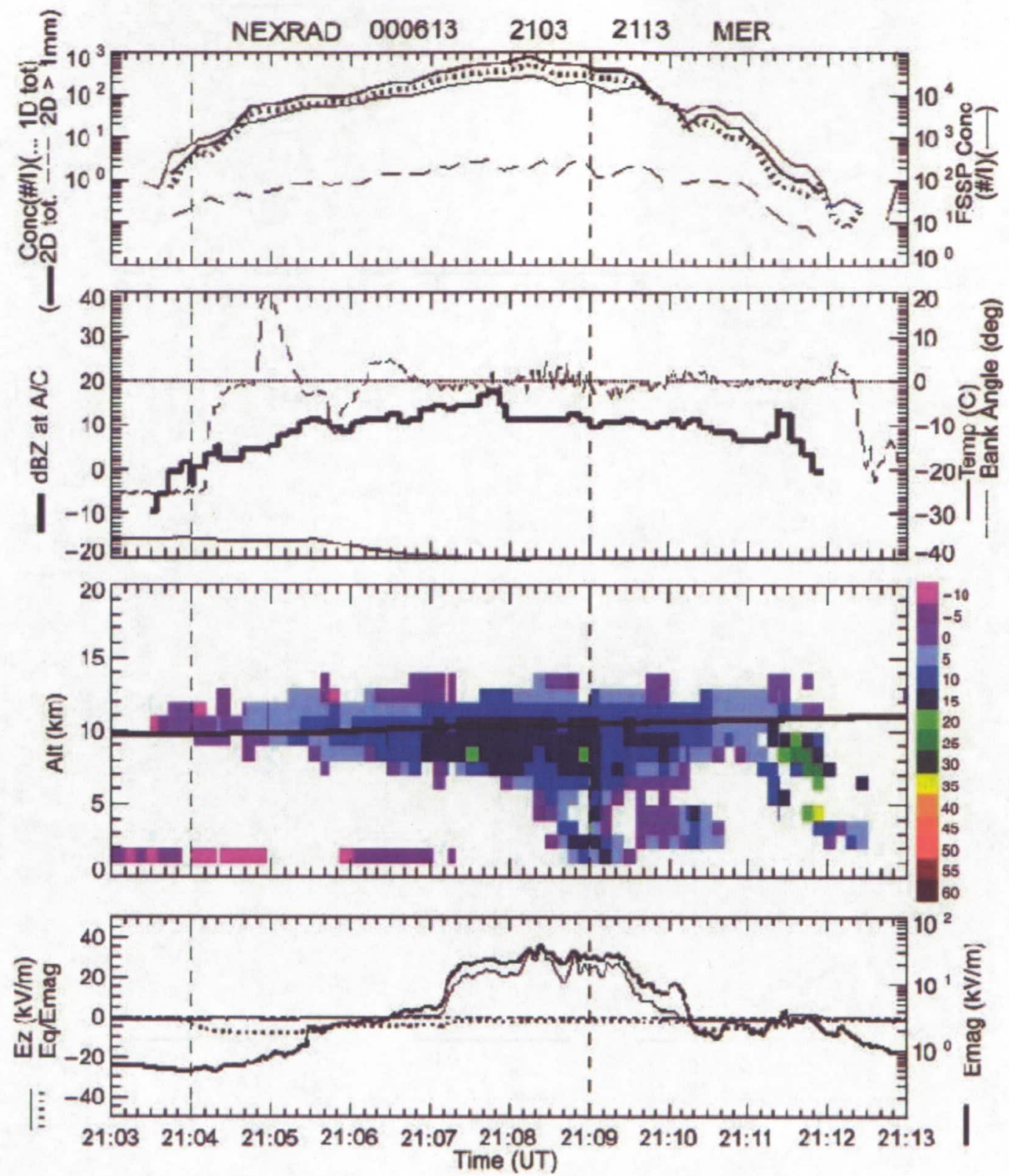

Figure 2 MER plot for 2103 to 2113 on June 13, 2000. Top Panel: Particle concentrations from different instruments: FSSP total concentration = light, solid line; 2D-C total concentration $=$ bold, solid line; $2 \mathrm{D}-\mathrm{C}$ concentration $>1 \mathrm{~mm}=$ dashed line; 1D-C total concentration $=$ dotted line. Second panel: Reflectivity at the aircraft location, bank angle of the aircraft and ambient temperature. Third Panel: Curtain of radar reflectivity above and below the aircraft (the numbers to the right of the color scale show the upper limit of reflectivity for each color interval); bold line = aircraft altitude. Bottom panel: $E_{z}$, the vertical component of electric field, is a thin line and referenced to the linear scale on the left. $\mathrm{E}_{\mathrm{q}} / \mathrm{Emag}$, shown as a dotted line, is also referenced to the left scale. ( $\mathrm{E}_{\mathrm{q}}$ is the field due to the charge on the aircraft). Emag, the scalar magnitude of the vector field, is shown as a bold line and referenced to the log scale on the right. 
Even though this pass of the Citation was moderately close to the core of the storm 389 (Figure 1) and the core was still producing lightning, the Rosemount Icing Detector 390 showed no evidence of supercooled water being present. All passes were examined for 391 evidence of the presence of any supercooled liquid water in these anvils, but none was 392 found [Schild, 2002]. We have confidence in the ability of the Rosemount probe on the 393 Citation to detect supercooled liquid water because it did show supercooled liquid water 394 to be present in some convective cores. Although supercooled water was not present at 395 the aircraft penetration altitudes of 8 to $11 \mathrm{~km}$, the laboratory work of Jayaratne et al., 396 [1983] has shown that a limited amount of charge transfer can occur between colliding 397 ice particles, albeit very, very small. Dye and Willett [2006] argue that given the broad 398 ice particle size distributions and the extended times available for particle collisions in 399 long-lived anvils some charge transfer might be occurring, but at a much slower rate than 400 occurs in convective cores.

401 Particle concentrations in different size ranges are shown in Figure 3. Unlike the 402 abrupt increase in electric field (Figure 2), the concentration of particles in different size 403 ranges did not show abrupt changes but gradually varied as the Citation flew from the 404 edge of the anvil towards the more dense part of the anvil and then decreased more 405 rapidly on the western side of the anvil. The relative increase in concentration was larger 406 for the smaller particles (shown by the FSSP and the total concentration of the 1-DC and $4072 \mathrm{D}-\mathrm{C}$ probes) than for the larger particles (shown by particles $>1 \mathrm{~mm}$ from the $2 \mathrm{D}-\mathrm{C}$ and 408 HVPS). The concentration of particles $>3 \mathrm{~mm}$ (measured by the HVPS) changed near the 409 anvil edge, but there was not a distinct trend during most of the penetration. Note that the 
411 anvil edges as would be expected as a result of evaporation and mixing.

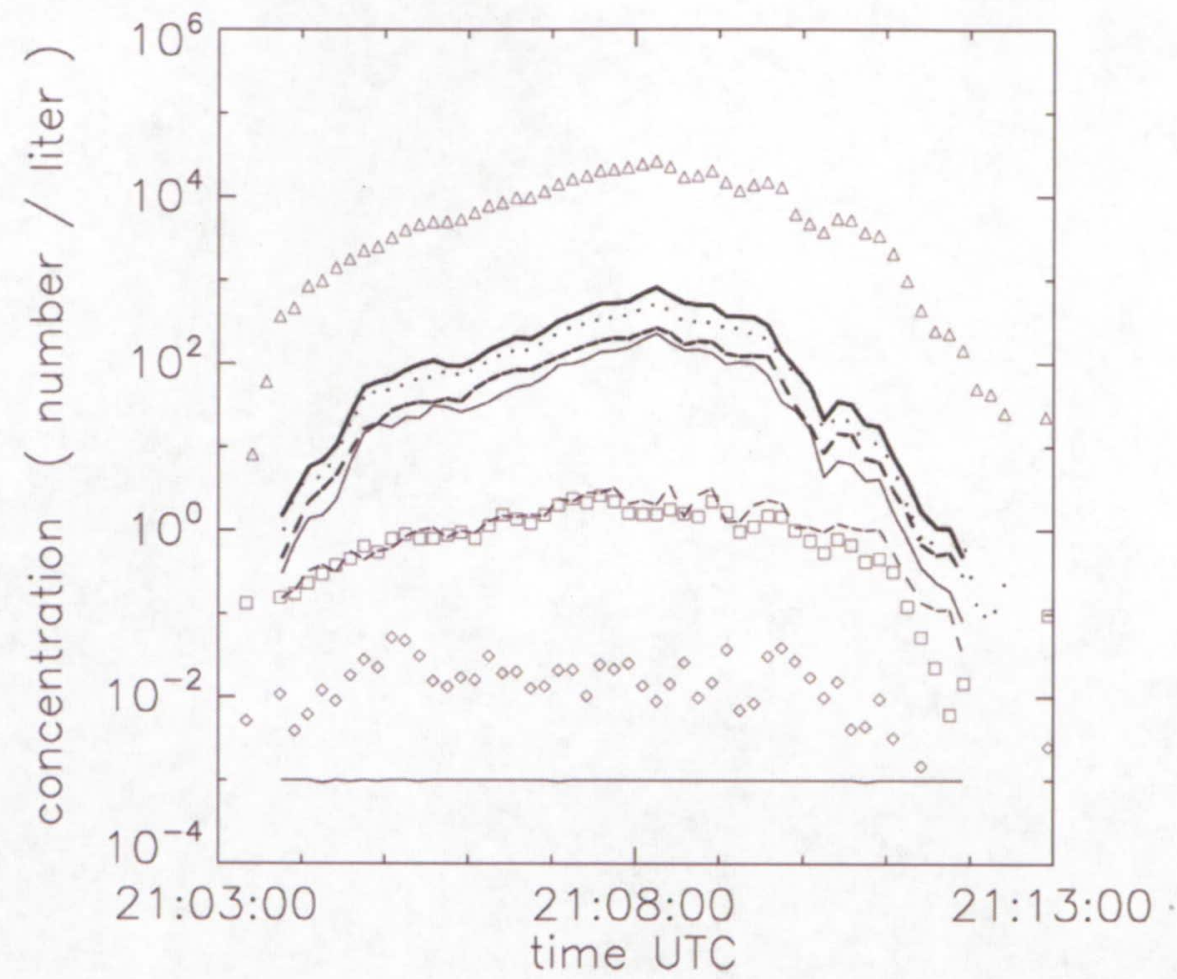

$$
\begin{aligned}
& \Delta \Delta \Delta \Delta \text { Total FSSP } \\
& \text { Total PMS 2D-C } \\
& \begin{aligned}
100 \text { to } 200(\mu \mathrm{m}) \\
-\cdots-\cdot 200 \text { to } 1000(\mu \mathrm{m})
\end{aligned} \\
& \ldots . .-2 D-C>1000(\mu \mathrm{m}) \diamond \diamond \diamond \diamond \diamond \text { HVPS above } 3000(\mu \mathrm{m}) \\
& \text { 2D-C Acceptance ratio*1.E-3 }
\end{aligned}
$$

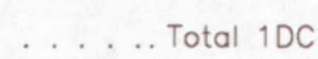

Figure 3 Time series plots of 10 second average values of particle number concentration for different probes and size ranges as indicated. The trace for the 2D-C > $1000 \mu \mathrm{m}$ is the dashed line almost on top of the squares for HVPS $>1000 \mu \mathrm{m}$.

Figure 4 shows examples of images from the 2D-C for the pass of Figure 1. Images

418 of the particles from the CPI and 2D-C showed that smaller particles were primarily 419 frozen cloud droplets. The intermediate-sized particles were usually irregularly shaped, 420 but pristine crystals such as plates were occasionally seen. The particles larger than 500 $421 \mu \mathrm{m}$ were primarily aggregates or polycrystals [Bailey and Hallett, 2002]. Near convective 
with the abrupt increases of electric field, but this deserves a more careful study.

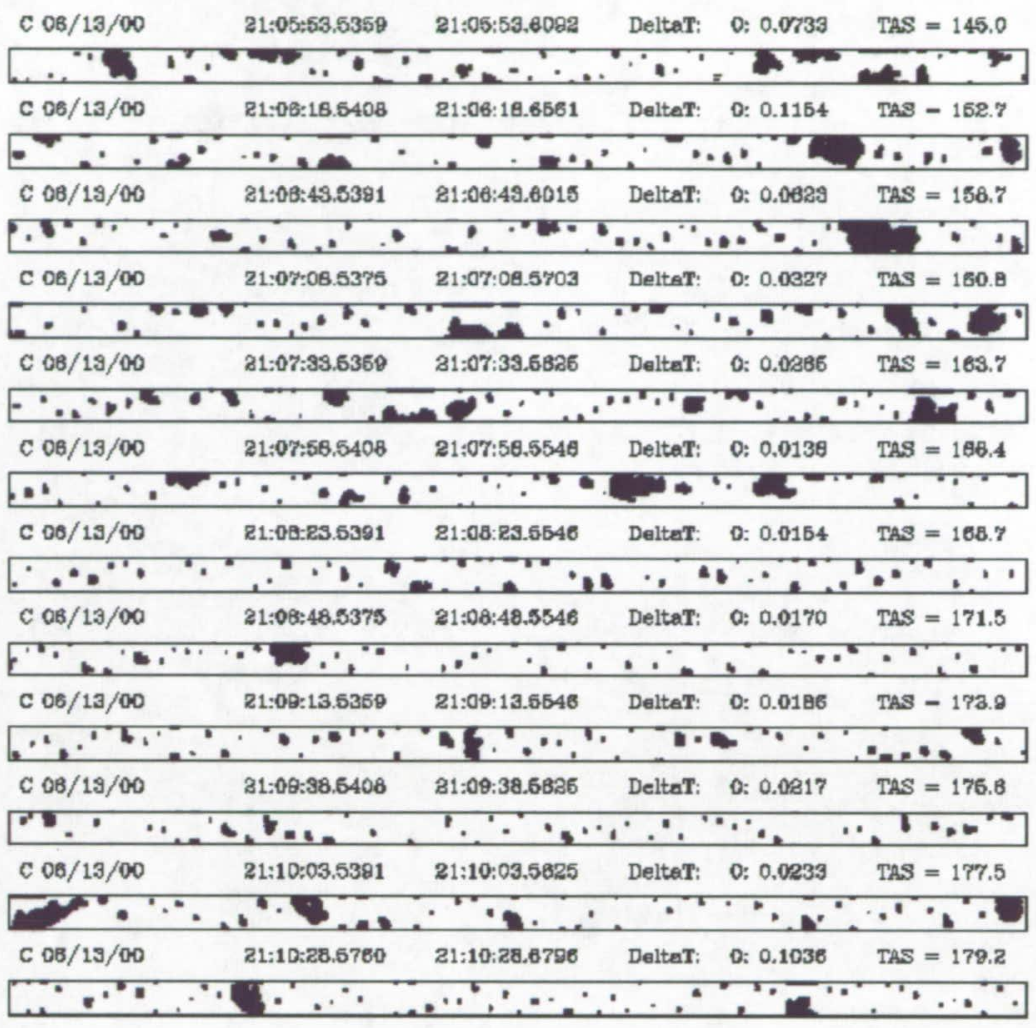

Figure 4 Buffers of particles imaged by the 2-DC probe. The vertical dimension of each row is $\sim 1 \mathrm{~mm}$. Text at the top of each buffer(row) shows the flight day $(\mathrm{M} / \mathrm{D} / \mathrm{Y})$; the start time of the first image in that buffer; the time of the last image in the buffer; DeltaT $=$ the elapsed time to fill the buffer; TAS $=$ true airspeed of the aircraft. Only one out of

431 every hundred buffers recorded is displayed. area at different locations across the anvil from near the edge to the dense part are presented in Figure 5. Because both size and concentration range over a few orders of

436 magnitude, these distributions are plotted in the form $d_{i}=f n\left(\log D_{i}\right) d\left(\log D_{i}\right)$, where $\operatorname{dn}_{i}$

437 is the concentration of particles in the size interval $i$ and $D_{i}$ is the mean size of particles 
438 in that interval. $\mathrm{dD}_{\mathrm{i}} / \mathrm{D}_{\mathrm{i}}$ was substituted for $\mathrm{d}\left(\log \mathrm{D}_{\mathrm{i}}\right)$ because the particles are accumulated 439 in linear size intervals. Thus, $d_{i}=f n\left(\log D_{i}\right) d D_{i} / D_{i}$. The units of $d n_{i} \operatorname{are~cm}^{-3}$.

440 The cross-sectional area for each particle was determined from the 2D-C and HVPS

441 images based upon the number of pixels occulted by the particle as it transited the laser

442 beam of that probe. Particle areas were then accumulated in the same size bins as were

443 the number concentrations. The particle size distribution plots in Figure 5 show the 444 agreement between the different probes as well as more details of the distributions 445 themselves. As previously noted in Figure 3, successive size distributions in Figure 5 446 show increases over the entire size range as time progressed, reaching a peak near 2108 447 when the Citation was flying in higher reflectivity.
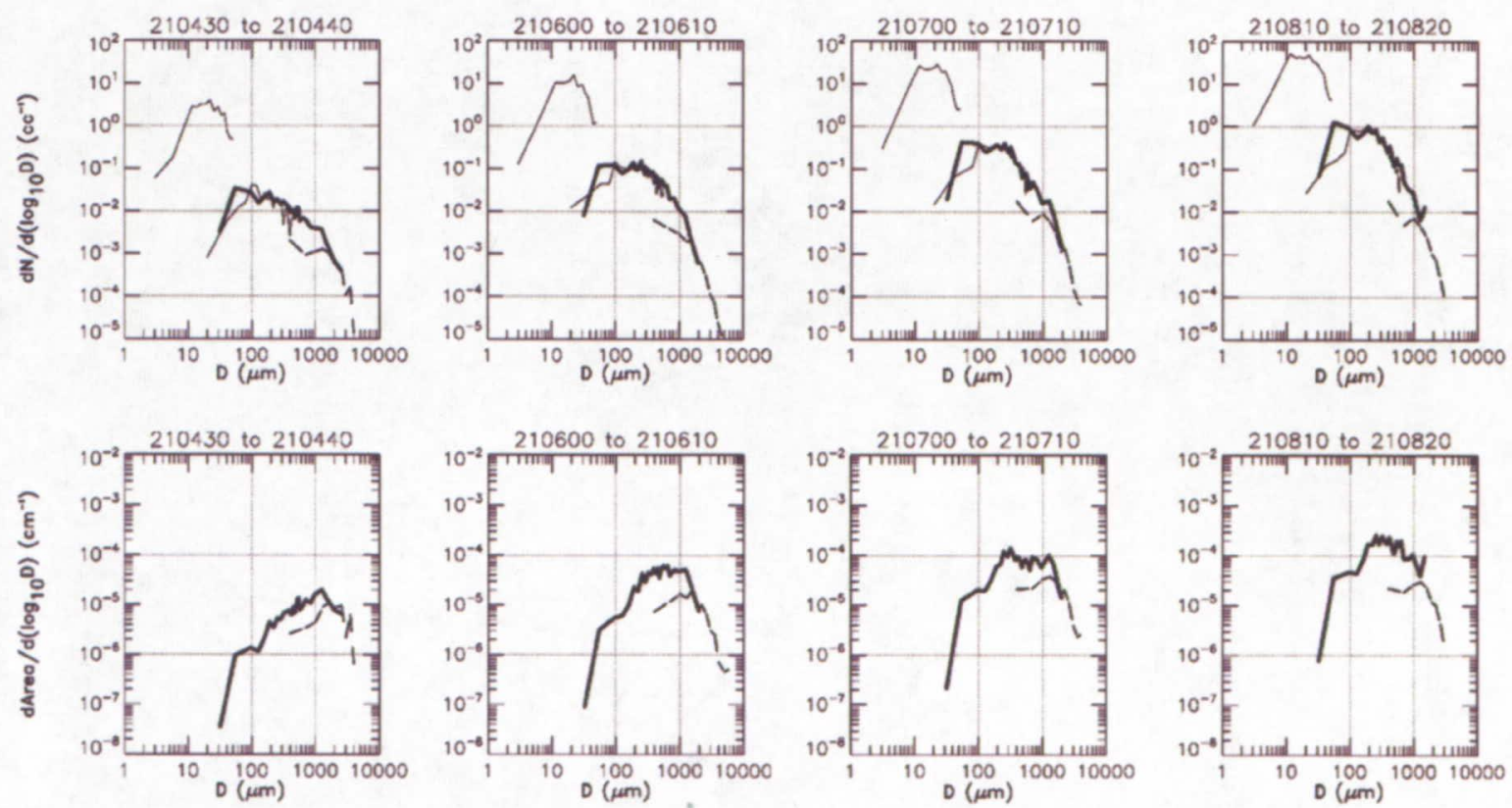

448

449

450

451

452

453

454

Figure 5 Top: Particle size distributions ( $10 \mathrm{~s}$ integration times) for the periods indicated during the Citation pass shown in Figures land 2. Bottom: Particle cross-sectional area distributions from the 2D-C and HVPS for the same $10 \mathrm{sec}$ time periods. Light line on the left side of number plots = FSSP; bold line $=2 \mathrm{D}-\mathrm{C}$; dotted line near the 2D-C line $=1 \mathrm{D}$ $\mathrm{C}$; dashed line on right of each plot $=$ HVPS. 
456 was at sizes of $50-300 \mu \mathrm{m}$, while the mode of cross-sectional area was at sizes of $200-$

$4572000 \mu \mathrm{m}$. Willett and Dye [2003] argue that the particle cross-sectional area is one of the

458 primary factors controlling the rate of decay of electric field in the anvil. The cross-

459 sectional particle area in different size ranges is plotted in Figure 6 for the measurements

460 from the 2D-C and the HVPS. This figure shows that in the main body of the anvil, the

461 area for sizes between 0.2 and $1 \mathrm{~mm}$ was almost one order of magnitude greater than the

462 area for particles $>1 \mathrm{~mm}$ in size. But near the edges of the anvil (near 2104 and 2011) the

463 particles $>1 \mathrm{~mm}$ contributed almost as much to the total area as the 0.2 to $1 \mathrm{~mm}$ particles.

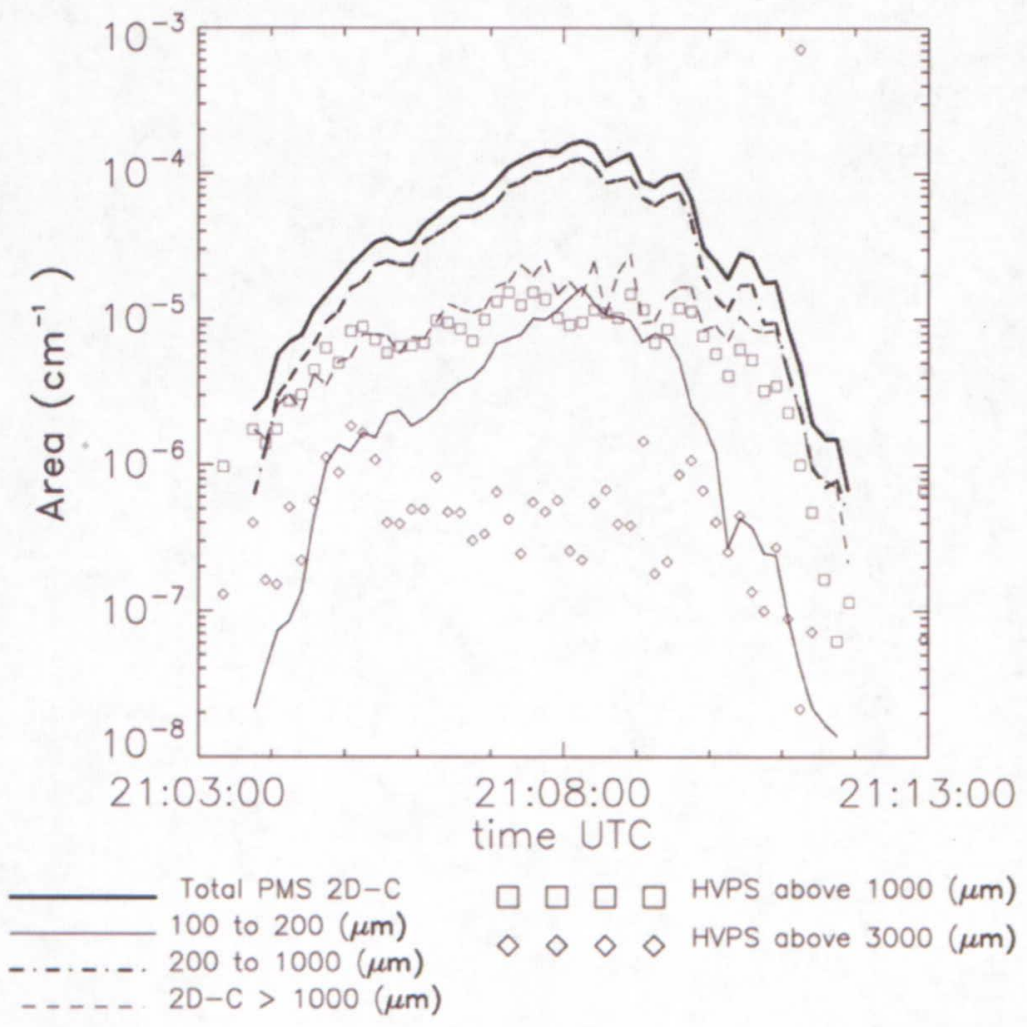

Figure 6 Time series plot of 10 second average values of particle cross-sectional 
467 The trace for the $2 \mathrm{D}-\mathrm{C}>1000 \mu \mathrm{m}$ is the dashed line almost on top of the squares for

468 HVPS $>1000 \mu \mathrm{m}$.

During this penetration across the anvil, the total particle cross-sectional area

471 increased by more than an order of magnitude from the anvil edge to the dense part of the

472 anvil. Consequently, the time expected for field decay is expected to increase by similar

473 amounts. Calculations for this penetration presented by Willett and Dye [2003] of "E

474 Time Scale", an estimated upper bound on the time required for the electric field

475 magnitude to decrease from 50 to near $0 \mathrm{kV} \mathrm{m}^{-1}$ based on an observed particle size

476 distribution, gave E Time Scale values of $\sim 300 \mathrm{~s}(5 \mathrm{~min})$ at the anvil edge but $\sim 5700 \mathrm{~s}$

477 (93min) in the dense part of the anvil near 2108. Thus, at the edge of anvils the electric

478 field decay should be very rapid but the decay is expected to be much, much slower in the

479 dense part of the anvil. Because sedimentation and turbulent mixing, leading to

480 evaporation, are the main mechanisms acting to erode the particle size distribution, the

481 rates of mixing and sedimentation may also be important factors in determining the

482 electric field decay.

On June $24^{\text {th }}$ wide spread convection started at 1630 with a cold front approaching

486 from the north. By 1800 storms covered central Florida with a line of strong convection

487 oriented along the east coast moving over KSC and Cape Canaveral. One of these cells

488 spawned a tornado that touched down in the Eastern Range at 1830. The Citation took off

489 at 1803 and almost immediately climbed into an anvil that extended $40 \mathrm{~km}$ to the

490 northeast of KSC. It then made several penetrations in the northeast and southwest 
491 directions moving away from and towards the line of convective cores, along and into the

492 direction of the wind. The track of the aircraft toward the convection from 1849 to 1858

493 is shown overlaid on CAPPIs in Figure 7. The figure shows the anvil ahead of the line of

494 convection and a trailing stratiform region behind the line, characteristics of mesoscale

495 convective systems. The corresponding MER plot of particle concentration, reflectivity

496 curtain along the aircraft track and electric field measurements is presented in Figure 8.

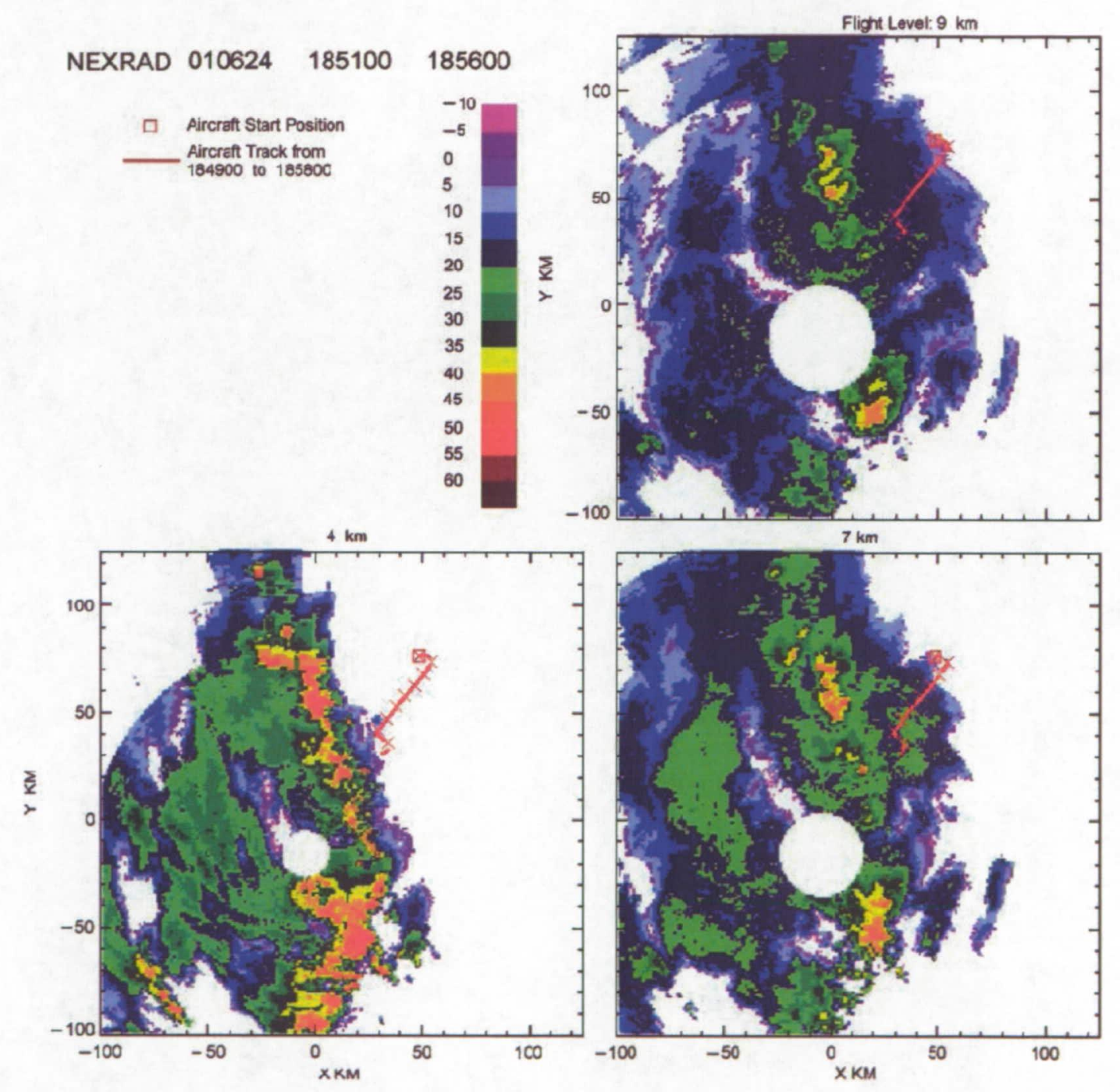


Figure 7. CAPPIs of reflectivity at 4, 7 and $9 \mathrm{~km}$ for June 24, 2001 from the

500 NEXRAD 1851 to 1856 volume scan with aircraft track from 1849 to 1858 overlaid in

501 red. The initial aircraft position is shown by a square with Xs plotted at each successive

502 minute along the track.

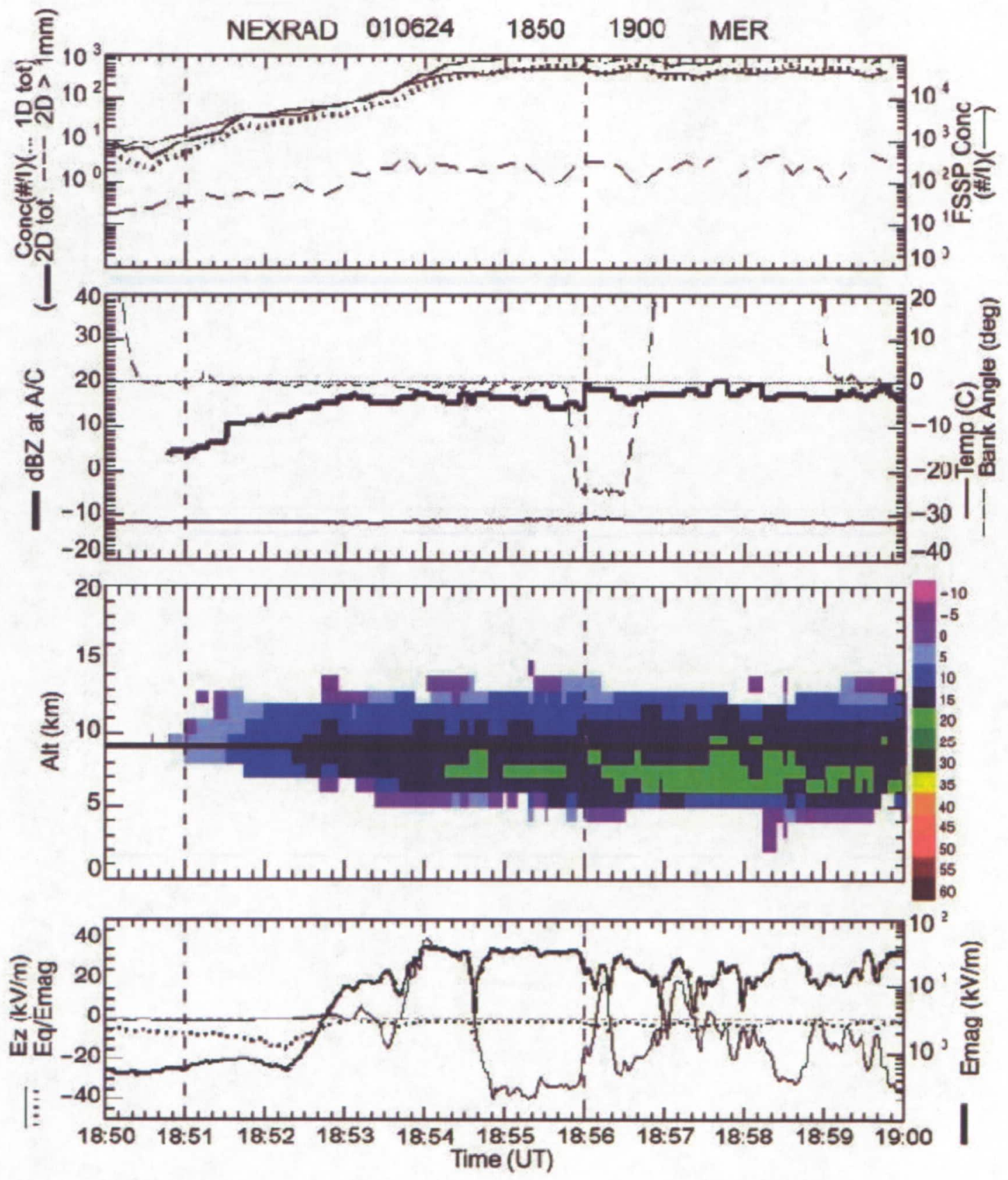

Figure 8 Same as figure 2 except 1850 to 1900 on June 24, 2001. 
$506 \quad$ Figure 8 shows an example of the changes in electric field observed when

507 penetrations were made from the downwind tip of the anvil towards the convective core

508 along the anvil axis. Particle concentrations and reflectivity increased smoothly from the

509 edge of the anvil inward but there was an abrupt, rapid increase in electric field (between

$510 \quad 1852$ and 1853 ) even in this intense storm, which was very actively producing lightning

511 at the time of this penetration. As with the June $13^{\text {th }}$ case of Figure 2, the field increase

512 occurred near a reflectivity of 10 to $15 \mathrm{dBZ}$. The bottom panel of Figure 8 shows large

513 variability and changes in polarity of Ez during this constant altitude pass, indicating the

514 complex charge structure of this anvil.

515 Some of these field changes were probably produced by nearby lightning. The

516 LDAR VHF sources (not shown) showed that lightning extended out almost as far as the

517 western end of the Citation track at $\sim 1858$. The particle concentrations measured by the

518 2D-C on June $24^{\text {th }}$ (Figure 8) are a little higher than the maximum total 2D-C

519 concentration shown in Figure 2 for June 13th, but considering the intensity of this storm

520 were rather comparable. The electric field magnitude was also comparable for the two

521 cases.

522

523 4. Synthesis of Measurements in Anvils

524 In the previous section we showed examples of the electric field, particle

525 concentration, and radar reflectivity measurements for two separate anvils. In this and

526 following sections we examine the relationships between these parameters for all of the

527 ABFM II measurements in anvils. To examine these relationships we produced a dataset 
528 for each Citation flight that included $10 \mathrm{~s}$ averages of measurements of standard state

529 parameters; such as ambient temperature, aircraft altitude, attitude and position; the three

530 components and magnitude of the electric field; and particle concentrations in different

531 size categories for each of the particle probes. These airborne measurements were then

532 merged with measurements of the reflectivity at the aircraft location and other spatial

533 averages of reflectivity centered on the time and position of the aircraft. In this section, in

534 order to reduce the statistical uncertainty in the particle concentration measurements and

535 the point-to-point scatter in reflectivity values, we have used $30 \mathrm{~s}$ averages of aircraft

536 measurements and 3-km cube averages of reflectivity. At a flight speed of 100 to $120 \mathrm{~m}$

$537 \mathrm{~s}^{-1} 30 \mathrm{~s}$ corresponds to a distance of 3.0 to $3.6 \mathrm{~km}$.

538 Although several different types of clouds were sampled by the aircraft during the

539 ABFM II project, we present here only those measurements made in or near anvils. We

540 defined an anvil as a cloud formed by transport away of material from the convective

541 core(s) by upper level winds or divergence at the top of a convective core. To be

542 considered an anvil, we further required that the cloud in question had a radar definable

543 base without precipitation reaching the ground. This then excluded some measurements

544 that were made during penetrations near convective cores where precipitation was

545 reaching the ground or in precipitating stratiform regions The total number of $30 \mathrm{~s}$

546 averages in this composite data set of anvil measurements was 2190 from 29 different

547 anvils and 79 separate penetrations. Most of the aircraft penetrations were at altitudes of $548 \quad 8$ to $10 \mathrm{~km}$.

550 4.1. Similarity of the Microphysical Properties of Dense Anvils 
551 The microphysical measurements in the dense part of the anvils, i.e. the regions

552 with the highest reflectivity and greatest particle concentrations showed a lot of similarity

553 from flight to flight and anvil to anvil. This is in part because $>65 \%$ of the measurements

554 in anvils made during ABFM II were at altitudes of 8 to $9.3 \mathrm{~km}$. The similarity in the

555 particle size distributions in the dense part of the anvils is shown in Figure 9 where the

556 concentration of particles $>1 \mathrm{~mm}$ measured by the $2 \mathrm{D}-\mathrm{C}$ for each $30 \mathrm{sec}$ period is plotted

557 versus the total concentration of particles measured by the $2 \mathrm{D}-\mathrm{C}$. The measurements were

558 broken into 2 groups, those with field magnitudes $>=10 \mathrm{kV} \mathrm{m}^{-1}$ (black) and those with

559 field magnitudes $<10 \mathrm{kV} \mathrm{m}^{-1}$ (gray).

560 Figure 9 shows that there is an almost linear relationship in this log-log plot in the

561 dense part of the anvils where the field magnitude was $>10 \mathrm{kV} \mathrm{m}^{-1}$. A linear least square

562 fit to the logarithms of those points with field magnitude $>=10 \mathrm{kV} \mathrm{m}^{-1}$ (the 456 black

563 points) had a correlation coefficient of 0.69 , which has high statistical significance. This

564 best fit line shows almost two orders of magnitude increase of the total 2D-C

565 concentration for each order of magnitude increase in the concentration of particles

566 greater than $1 \mathrm{~mm}$. This result is similar to that shown in Figure 3 for only one

567 penetration, i.e. as the aircraft flew from the edge of the anvil toward the dense part of the

568 anvil the concentration of small and intermediate-sized particles increased more than the

569 concentration of the larger particles. 


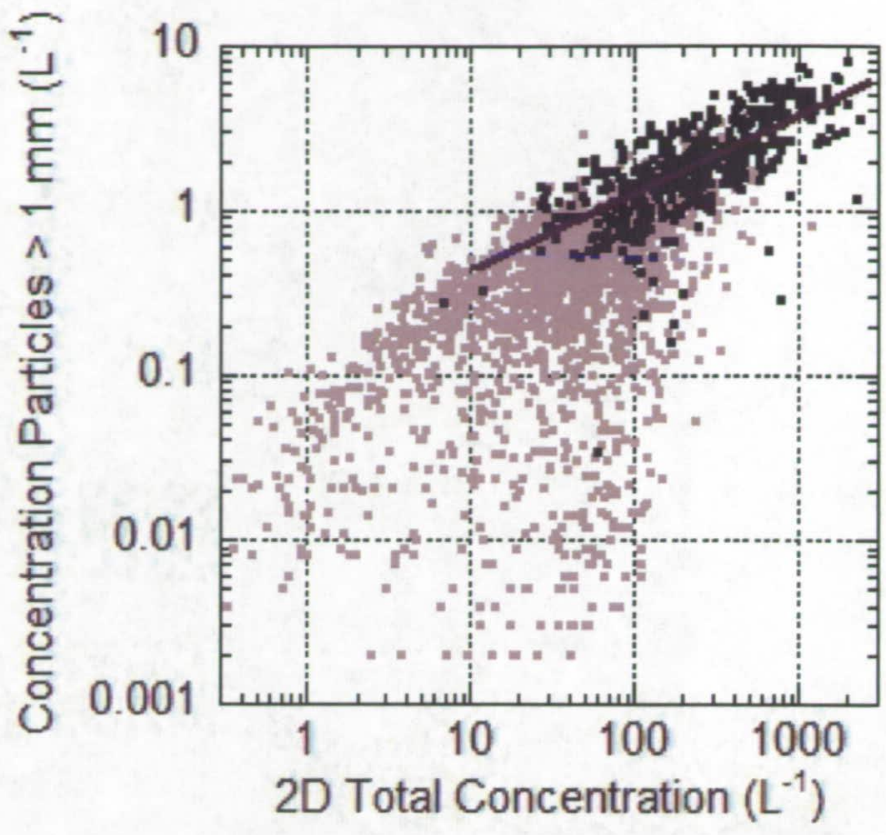

571

572

573

574

575

576

577

578

579

580

Figure 9 Scatter-plot of $30 \mathrm{sec}$ averages of total particle concentration measured by the $2 \mathrm{D}-\mathrm{C}$ vs. the concentration of particles $>1 \mathrm{~mm}$ measured by the $2 \mathrm{D}-\mathrm{C}$. The points with field magnitude $>=10 \mathrm{kV} \mathrm{m}^{-1}$ are plotted in black while those with field $<10 \mathrm{kV} \mathrm{m}^{-1}$ are gray. There are a total 1998 points in this plot of which 456 points had field magnitudes $>=10 \mathrm{kV} \mathrm{m}^{-1}$. The straight line is a least square fit to only those points with $\mathrm{E}>=10 \mathrm{kV} \mathrm{m}^{-1}$.

Although there is scatter, the variation of particle concentration from case to case was within a factor of 2 to 3 in the dense anvils. In the edges of the anvil where concentrations are smaller, there was much more variation. The majority of the points with high concentrations of both small and large particles were the same regions with fields magnitude $>10 \mathrm{kV} \mathrm{m}^{-1}$. Contrastingly those regions with lower particle concentrations corresponding to edges or other less dense parts of the anvil were almost devoid of points with field $>10 \mathrm{kV} \mathrm{m}^{-1}$.

Both aggregation and sedimentation should alter the particle size distribution in an anvil and we have some evidence of this in the measurements made during spiral descents. On 24 June 2001 a descent was made from 9.2 to $4.7 \mathrm{~km}\left(-31\right.$ to $\left.-4{ }^{\circ} \mathrm{C}\right)$ from 
5891947 to 2001 in a region that was the transition zone between the anvil and a broad mid-

590 level stratiform region with $20-25 \mathrm{dBZ}$ reflectivity at $6-8 \mathrm{~km}$ altitude, but without

591 precipitation reaching the ground. The electric field magnitude was $10-30 \mathrm{kV} \mathrm{m}^{-1}$ for

592 much of the descent. The concentration of the small and intermediate-sized particles

593 decreased by a factor of 3 to 4 and the concentration of the particles $>3 \mathrm{~mm}$ increased by

594 a factor of about 5, thus showing the effects of sedimentation and aggregation. The

595 concentration of particles $>1 \mathrm{~mm}$ increased less than a factor of 2 . In the altitude interval

596 of 9.2 to $8 \mathrm{~km}$, where $>65 \%$ of the ABFM II anvil penetrations were made, the decrease

597 in small to mid-sized particles was small and the increase in $>3 \mathrm{~mm}$ particles was less

598 than a factor of 2.

599

$600 \quad 4.2$ Relationship between Radar Reflectivity and Particle Concentration

601 Figure 10 shows the average reflectivity in a 3-km cube centered on the aircraft

602 altitude and location plotted as a function of particle concentration for different size

603 ranges. The reflectivity of the $1-\mathrm{km}$ grid pixels was averaged in $\mathrm{dBZ}$ and pixels with no

604 detectable reflectivity or reflectivity $<0 \mathrm{dBZ}$ were not included in the average. To be

605 included in the data set, we required that at least 16 of the 27 one kilometer pixels in the

$6063-\mathrm{km}$ cube contain reflectivity above a threshold of $0 \mathrm{dBZ}$. Three kilometers was chosen

607 as it approximately corresponded to the distance flown by the aircraft in $30 \mathrm{~s}$. In addition,

608 the 3-km cube average smoothed some of the pixel to pixel variation of the $1-\mathrm{km}$ gridded

609 radar measurements and also helped to compensate for the scan gaps in radar coverage

610 when the radar elevation sweeps did not overlap.

611 

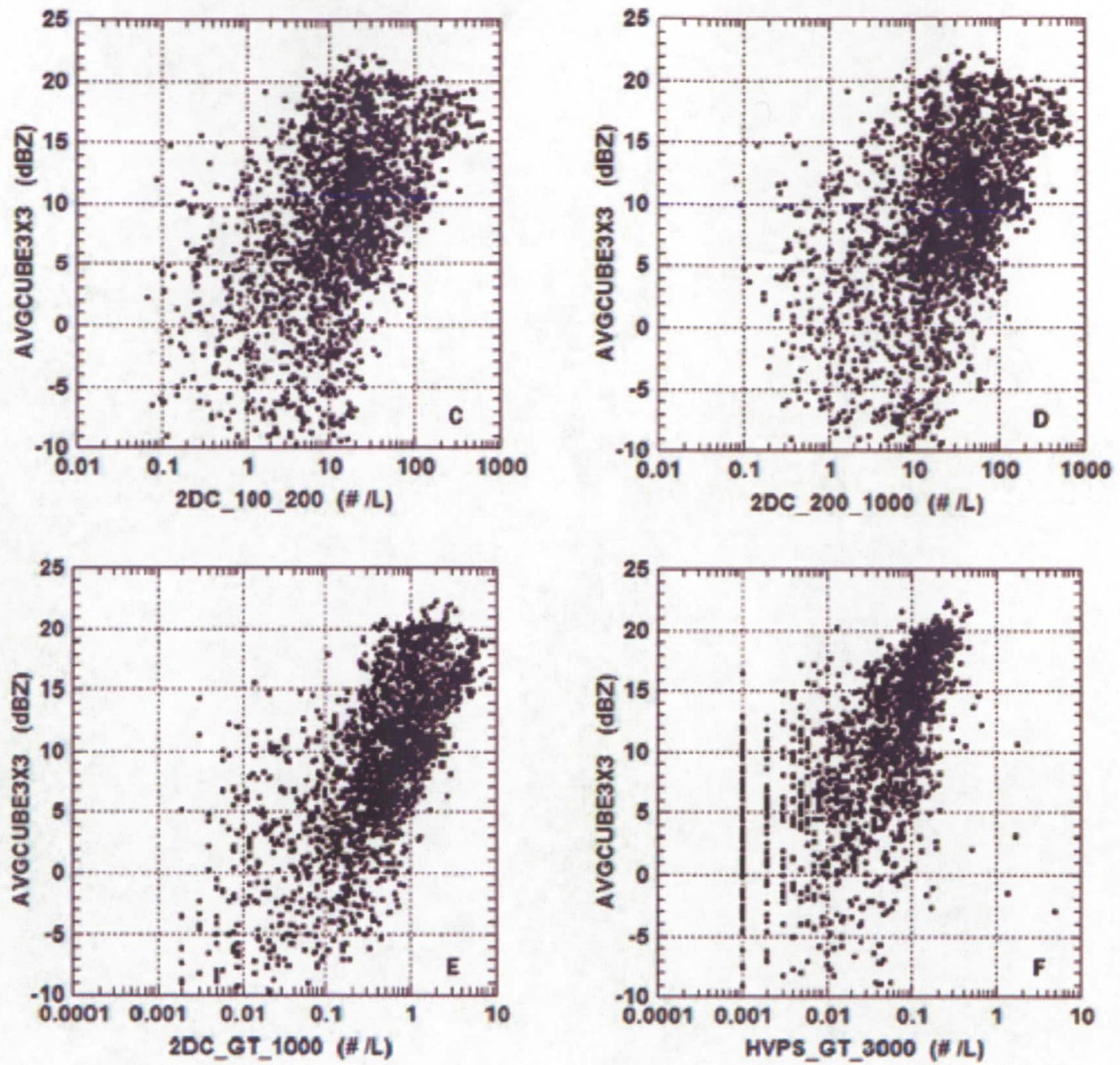

613

614

615

616

617

618

619

620

200-1000 $\mu \mathrm{m}$ particle size ranges, all plots showed a trend of increases in reflectivity

Figure 10 Scatter-plots of particle concentrations in different size categories (100$200 \mu \mathrm{m} ; 200-1000 \mu \mathrm{m} ; 2 \mathrm{D}-\mathrm{C}>=1 \mathrm{~mm}$; and HVPS $>=3 \mathrm{~mm}$ ) vs. the average reflectivity within a 3-km cube centered on the altitude and position of the aircraft. There were about 2000 points in $\mathrm{C}, \mathrm{D}$, and $\mathrm{E}$ and 1500 in $\mathrm{F}$.

Although there is a lot of scatter in these plots, particularly for the $100-200 \mu \mathrm{m}$ and

623 reflectivity in $\mathrm{dBZ}$ vs. the logarithm of particle concentration gave correlation

624 coefficients of $0.50,0.58,0.68$ and 0.58 for plots C, D, E and F, respectively. Although 
625 the correlation coefficient of plot $\mathrm{F}$ (for the concentration of particles $>3 \mathrm{~mm}$ ) is less than

626 that for plot $\mathrm{E}$ (for the concentration of particles $>1 \mathrm{~mm}$ ), visually there appears to be less

627 scatter in plot $\mathrm{F}$ for points with the greatest particle concentration. Because the radar

628 reflectivity is proportional to the sixth power of particle size, we expect the reflectivity to

629 be dominated by the concentration of the largest particles, as suggested in Figure 10. The

630 ABFM II observations in these Florida anvils do not show unusual behavior in the

631 relationship between particle concentration and reflectivity. Figure 10 is shown here

632 primarily to help interpret the results of the next two sections, where the electric field

633 magnitude is shown not to have a well behaved relationship to either particle

634 concentration or radar reflectivity.

635 4.3 Relationship between Electric Field and Particle Concentration

636 The relationship between electric field and particle concentration is shown in Figure

637 11. Unlike the trend of increasing reflectivity with increasing particle concentration

638 shown in Figure 10, both the total 2D-C concentration and the concentration of particles

$639>1 \mathrm{~mm}$ shown in Figure 11 exhibit a clear change in character at 1 to $2 \mathrm{kV} \mathrm{m}^{-1}$. For
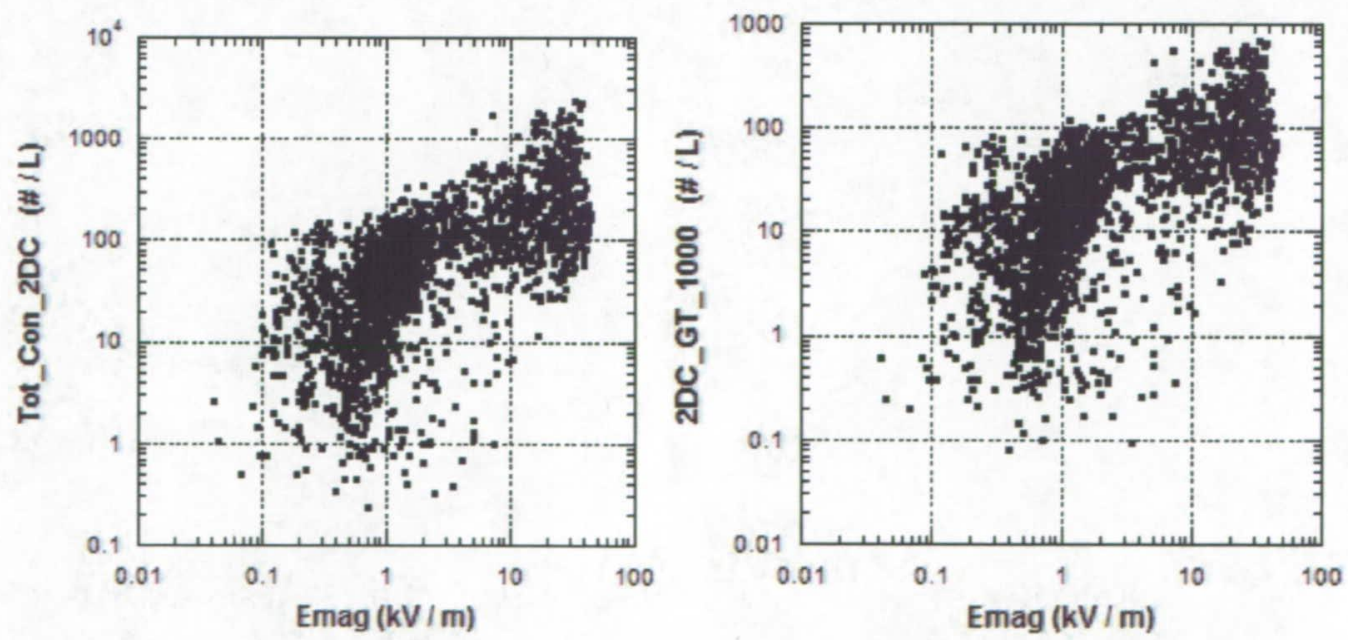

Figure 11 Scatter-plot of electric field vs total particle concentration measured by 642 the 2D-C (left) and concentration of particles $>1 \mathrm{~mm}$ size (right) for the ABFM II anvil 
643 data set. Each figure contains about 2100 separate $30 \mathrm{sec}$ averages. Note that the

644 concentration scale is different in the two plots.

645

646 electric fields $>2 \mathrm{kV} \mathrm{m}^{-1}$ there was a gradual, but not pronounced, increase in the particle

647 concentrations as electric field increased from 2 to $>30 \mathrm{kV} \mathrm{m}^{-1}$. But for electric fields $<2$

$648 \mathrm{kV} \mathrm{m}^{-1}$ there is a " $\mathrm{knee}$ " and much more variation in the particle concentration. This knee

649 is a result of the rather abrupt transition in electric field noted previously and shown in

650 Figures 2 and 8 . The plots show a threshold behavior with only a few points in the lower

651 right part of the plots. The points in Figure 11 are distributed throughout the anvil cases.

652 Thus the knee in these plots was not from any specific case but was a feature that is

653 representative of all the ABFM II anvil measurements. This change in behavior suggests

654 a change in physical processes or perhaps in the balance between different physical

655 processes. We will explore some possible explanations for this change in behavior in

656 Section 6 below.

$658 \quad 4.4$ Relationship between Electric Field and Reflectivity

659 The relationship between the electric field magnitude and the 3-km cube average

660 reflectivity is presented in Figure 12. Like the plots of particle concentration versus field

661 magnitude shown in Figure 11, these plots show a change of character or knee at 1 to 2

$662 \mathrm{kV} \mathrm{m}^{-1}$. This is not too surprising in view of the monotonic trends shown in Figure 10

663 above. For electric fields less than $2 \mathrm{kV} \mathrm{m}^{-1}$, the average reflectivity spanned a range

664 from -10 to $>20 \mathrm{dBZ}$ with many points having a field $<3 \mathrm{kV} \mathrm{m}^{-1}$ but a reflectivity of 10

665 to $20 \mathrm{dBZ}$, showing that higher reflectivity is not necessarily a good predictor of strong

666 electric fields. However, only a few points with electric field $>3 \mathrm{kV} \mathrm{m}^{-1}$ have a 
669

reflectivity less than $5 \mathrm{dBZ}$. There is a reflectivity threshold below which thunderstorm strength electric fields $\left(>\sim 5 \mathrm{kV} \mathrm{m}^{-1}\right)$ were not found in ABFM II anvils.

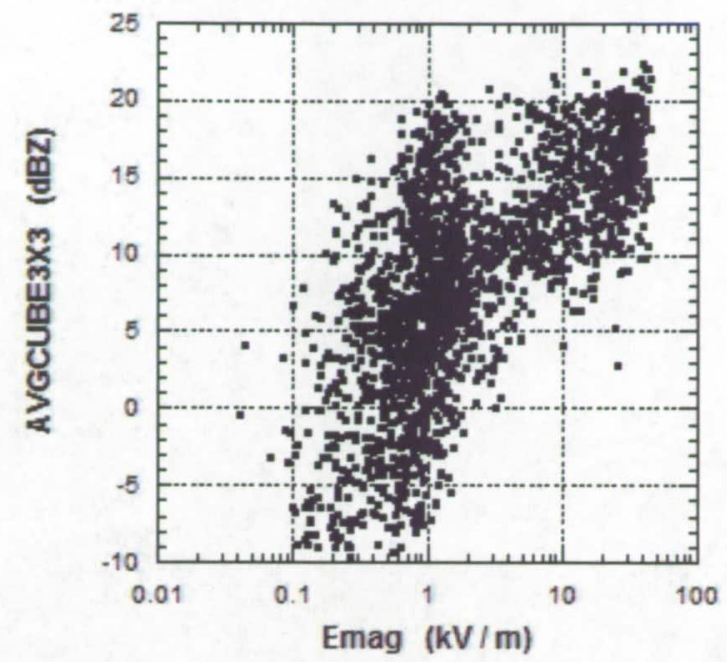

Figure 12 Scatter-plot of electric field magnitude vs. $3 \times 3 \times 3 \mathrm{~km}$ cube average reflectivity for the ABFM II anvil data set.

5. Exploring Possible Radar Parameters for Use in an LLCC

The results shown in Figure 12 gave promise that a radar-based reflectivity parameter might be a useful diagnostic for determining the possibility of high electric fields in anvils and for developing improved Lightning Launch Commit Criteria (LLCC) for anvils. However, since there were a few points in the lower right quadrant of Figure 12 that had electric fields $>3 \mathrm{kV} \mathrm{m}^{-1}$ with average reflectivity less than $5 \mathrm{dBZ}$, we explored other possible spatial averages of reflectivity.

Before examining other radar parameters we wanted to know the maximum electric field that might present a threat for triggering lightning in these anvils. This is a topic of current research and a detailed discussion is beyond the scope of this paper. Extrapolation of the rocket triggered lightning studies of Willett et al. [1999] to anvil altitudes 
686

687 vehicles like the Space Shuttle and the Titan booster at anvil altitudes. This is the value 688

689

690

691

692

693

694

695

696

697

698

699

700

701

702

703

704

705

706

707

suggested that electric fields $<3 \mathrm{kV} \mathrm{m}^{-1}$ are not capable of triggering lightning to large currently used by the Air Force and NASA in the existing LLCC. By way of comparison, during ABFM II in dense parts of anvils field magnitudes of $30-60 \mathrm{kV} \mathrm{m}^{-1}$ were frequently observed during penetrations near the convective cores of storms and $10-30$ $\mathrm{kV} \mathrm{m}^{-1}$ in anvils tens of kilometers downwind of the core. Fields of $100-150 \mathrm{kV} \mathrm{m}^{-1}$ have often been observed in mature thunderstorms [MacGorman and Rust, pp. 174-177, 1998].

Figure 13 shows the relationships between electric field and 4 different spatial averages of reflectivity. In these plots we have used $10 \mathrm{~s}$ averages of electric field and we have filtered the entire anvil data set to remove points for which the aircraft was within $20 \mathrm{~km}$ of a convective core with reflectivity $>35 \mathrm{dBZ}$ at $4 \mathrm{~km}$ altitude or greater in order to avoid regions of rapid field intensification associated with the cores. We also have removed points for which the aircraft was within $20 \mathrm{~km}$ of any lightning detected by either LDAR or the CGLSS within the previous $5 \mathrm{~min}$ in order to avoid regions directly influenced by recent lightning. Additionally, we limited these averages of reflectivity to altitudes $>=5 \mathrm{~km}$, roughly the freezing level in Florida during the summer. The plot on the lower right shows results for the $3-\mathrm{km}$ cube reflectivity average and is similar to Figure 12 except for the core and lightning filters mentioned above and except for $10 \mathrm{~s}$ averages of electric field rather than the $30 \mathrm{~s}$ averages used previously. The results are similar to those of Figure 12 with a few points that have $\mathrm{E}>3 \mathrm{kV} \mathrm{m}^{-1}$ and reflectivity $<5$ $\mathrm{dBZ}$. 

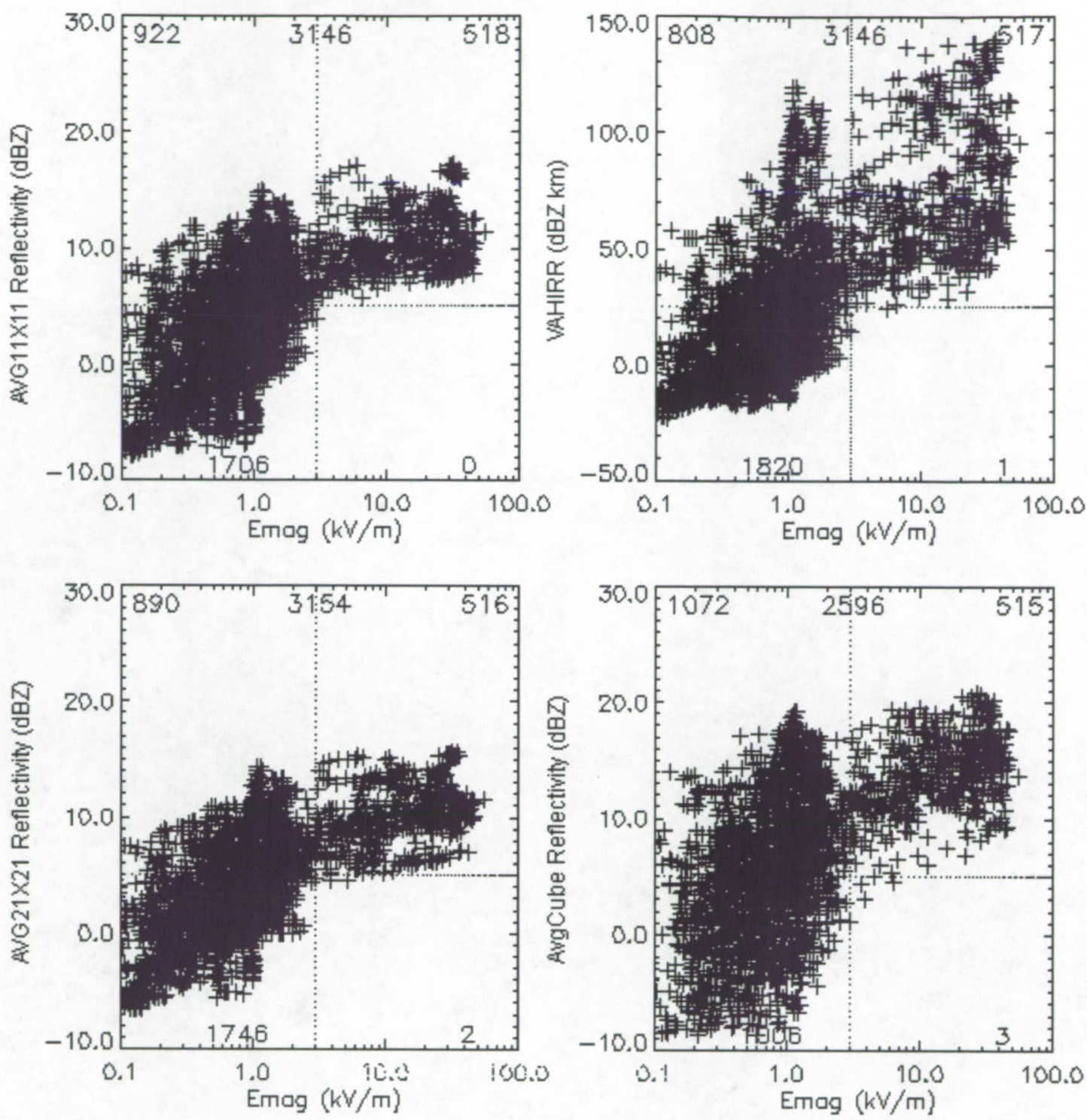
averages of reflectivity. (See the text.) The number in the top center of each plot gives the total points in that plot with the numbers near the corners of each plot showing the number of data points in each quadrant of that plot. The text at the top indicates which

718 has the possibility of including regions of high reflectivity that might contain substantial 
719 charge near, but not at the aircraft position. It has the additional advantage that averaging 720 over a larger volume will compensate for any unsampled scan gaps and radar propagation

721 effects. The upper left plot labeled AVG $11 \times 11$ Reflectivity on the ordinate shows the 722 average $\mathrm{dBZ}$ reflectivity calculated from $5 \mathrm{~km}$ altitude (approximately the $0 \mathrm{C}$ level) to

723 the top of the cloud over an $11 \times 11 \mathrm{~km}$ area extending horizontally $5 \mathrm{~km}$ in the north, 724 south, east and west directions from the $1 \mathrm{~km}$ grid point containing the aircraft position.

725 The lower left plot labeled AVG $21 \times 21$ Reflectivity on the ordinate is similar except that

726 the volume average is calculated over an area extending $10 \mathrm{~km}$ in each direction from the 727 aircraft position. These 2 plots show very similar results.

728 A shortcoming of the volume averages is that averaging the reflectivity within a box

729 or column ignores potentially important information on the depth of the anvil. A thin

730 anvil might have the same average reflectivity as a much deeper anvil, but deeper anvils

731 are more likely to contain charge. The upper right plot of Fig. 13 shows the $11 \times 11$

732 Volume Averaged Height Integrated Radar Reflectivity (VAHIRR) [Bateman et al.,

733 2005]. This parameter was calculated by multiplying the $11 \times 11$ reflectivity averaged in

$734 \mathrm{dBZ}$ by the average radar thickness of the anvil in $\mathrm{km}$ over the $11 \mathrm{x} 11 \mathrm{~km}$ area. Unlike the

$73511 \times 11$ average reflectivity.plot, in the upper right quadrant the 11x11VAHIRR plot

736 shows high values of reflectivity with high values of field magnitude. It has only one

737 point in the lower right quadrant for VAHIRR $<25 \mathrm{dBZ} \mathrm{km}$ and electric field $>3 \mathrm{kV} \mathrm{m}^{-1}$.

738 A statistical analysis of extreme values [Reiss and Thomas, 2001] by Dr. Harry C. Koons

739 (Personal communication) for the $11 \times 11 \mathrm{~km}$ VAHIRR $\leq 10 \mathrm{dBZ} \mathrm{km}$ (equivalent to an

740 average of $10 \mathrm{dBZ}$ in a $1 \mathrm{~km}$ thick anvil, or $2 \mathrm{dBZ}$ in a $5 \mathrm{~km}$ thick anvil) showed that the

741 probability of having an electric field $>3 \mathrm{kV} \mathrm{m}^{-1}$ was less than 1 in 10,000 . VAHIRR is 
742 now being used by the Air Force and NASA in new Lightning Launch Commit Criteria

743 for anvils.

744

745 6. DISCUSSION

746 In previous sections we have shown that along a penetration the electric field

747 increased abruptly in contrast to the more smoothly changing particle concentrations or

748 reflectivity. This behavior was apparent for individual penetrations as well as in a

749 statistical sense for all of the anvil measurements. In this section we explore possible 750 causes for this behavior.

751

$752 \quad 6.1$ Screening Layers

753 At cloud boundaries the electrical conductivity changes significantly. If there is a

754 component of electric field normal to the cloud boundary fast ions can attach to cloud

755 particles to produce charge layers that tend to "screen" the outside air from elevated fields

756 in the lower-conductivity interior of the cloud [e.g., Klett, 1972], hence the name

757 screening layer. Vonnegut et al. [1966] and Blakeslee et al, [1989] have measured strong

758 electric fields above the top of convective regions of thunderstorms and have concluded

759 that screening layers were not present in the convective turrets because of rapid mixing

760 and entrainment near the cloud boundaries. At the top and bottom of stratified anvil

761 clouds that contain net charge, however, balloon-borne measurements have found

762 screening layers a few hundred meters thick [e.g., Winn et al., 1978; Marshall et al.,

763 1984; Byrne et al., 1989]. In principal, such layers might build up around the entire 
764 periphery of an electrified anvil, i.e., on the vertical edges as well as on the top and 765 bottom.

766 There are two cases that concern us here. First, our observations of abrupt increases 767 in field magnitude when flying horizontally into anvils might be due to vertical screening 768 layers on the edges of these clouds. Such a vertically oriented charge layer near a cloud 769 boundary could only be caused by a significant horizontal component of the field from 770 net charge in the interior. If it existed, this layer of charge would produce a change in the 771 horizontal field component perpendicular to the cloud edge as the aircraft penetrated the 772 cloud.

773 There are several reasons to doubt this explanation of our observations. We are not 774 aware of any other measurements in the literature that document screening layers on the 775 vertical edges of anvils. Our ABFM II measurements of the three components of electric 776 field clearly show that the vertical component of the field, $E_{z}$, is almost always dominant 777 and usually a factor of 3 to 10 times or more as great as the $E_{x}$ or $E_{y}$ component. Because 778 the Citation penetrations were approximately perpendicular to the edge of the anvil, we 779 should be able to detect the presence of a vertical screening layer as an abrupt increase in 780 the magnitude of $E_{x}$ on entering or exiting the anvil, but we do not. Furthermore, the 781 abrupt change in field magnitude was often observed at large distances from the edge of 782 the anvil. For example, at 2107 in Figure 2 the abrupt field increase (primarily due to the 783 vertical component) occurred more than three minutes $(-22 \mathrm{~km})$ after the aircraft entered 784 the anvil. It is hard to imagine that turbulent mixing from the cloud edge would transport 785 screening-layer charge this far from the edge of the anvil and still maintain the sharp 786 gradient in field. Similarly, for July $24^{\text {th }}$ the abrupt increase was $>2 \frac{1}{2} \min (\sim 16 \mathrm{~km})$ from 
787 the downwind anvil tip detected by the particle probes. Merceret et al. [2006] show that

788 for ABFM II anvils the average distance inside the anvil boundary at which the field

789 magnitude exceeded $3 \mathrm{kV} \mathrm{m}^{-1}$ was about $3 \mathrm{~km}$.

790 The second case that concerns us here involves the horizontal screening layers that

791 are known to occur on the top and bottom boundaries of electrified anvils. During a

792 horizontal pass through such an anvil, the aircraft might dip into or out of a charge layer

793 that was not perfectly flat as a result of gravity waves or other dynamics within the cloud.

794 If the screening layer was sufficiently thin, this might result in the kind of abrupt

795 increases and decreases in field magnitude (dominated by the vertical component of the

796 field) that we observed, for example, in Figure 2.

797 We also doubt this as an explanation of the abrupt field increases that we observed.

798 In most cases when these events occurred, the Citation was flying well below (above) the

799 top (bottom) of the anvil. For example, in Figure 2 at 2107 the abrupt field change

800 occurred where the anvil thickness was 6 to $7 \mathrm{~km}$ and the aircraft was at least $2 \mathrm{~km}$ below

801 the cloud top. Again, it is hard to imagine that turbulent mixing would transport screening

802 layer charge this far from the top of the anvil and still maintain the sharp gradient.

803 Turbulent mixing would act to smear out charge and smooth out the gradient of electric

804 field. Similarly, for July $24^{\text {th }}$ the abrupt increase was approximately in the vertical center

805 of a $7 \mathrm{~km}$ thick anvil. In summary, it does not seem possible that screening layers could

806 explain an appreciable fraction of the sudden increases (and decreases) in field magnitude

807 that were observed during ABFM II.

808

809 6.2 Charge Transport from the Storm Core 
810 Charge separation via the non-inductive mechanism is thought to occur primarily in

811 moderate updrafts or updraft/downdraft transition zones because that is the region in

812 which supercooled liquid water, graupel and numerous smaller ice particles coexist [e.g.

813 Dye et al. 1986]. Since moderate updrafts and updraft/downdraft transition zones occupy

814 only a fraction of the horizontal area of the core of a storm, it seems reasonable to expect

815 that strong electric fields would not be present across the entire breadth of the anvil, even

816 near the convective core. The ABFM II measurements made near or only slightly

817 downwind of a storm core (such as seen in Figure 2 for the June $13^{\text {th }}$ case) indeed showed

818 that strong fields did not exist across the entire anvil.

819 If the abrupt changes in electric field occurred only during the cross anvil

820 penetrations, the limited extent of charge transport could explain the behavior of our

821 electric field versus particle concentration plots. However, Figure 8 for July 24, 2001

822 clearly showed an abrupt increase in electric field even when the aircraft flew along the

823 main axis of the anvil toward the core of the storm. The updraft cells in multi-cellular

824 storms, such as those investigated in ABFM II, often have lifetimes of 15 to 30 min and

825 are episodic in nature, with new updrafts forming and intensifying while others are

826 decaying. Evidence of this was clearly seen in the evolution of the reflectivity structure of

827 ABFM II storms. Consequently, the time periods of charge separation and outflow of

828 charged particles into the anvil should also be episodic. One would therefore expect that

829 the charge distribution in the anvil would be granular with some regions containing more

830 charge (stronger electric fields) than others. We see evidence of this in ABFM II

831 measurements. As a parcel containing charge moves downwind in the anvil, turbulent

832 mixing and electric field decay (see below) occur. These processes should reduce the 
833 gradient of electric field as well as the magnitude and thus the abruptness of electric field

834 changes. Both the limited fraction of the storm core from which charged particles are

835 advected, and the episodic nature of the updrafts are likely to play a role in explaining

836 some of the abrupt changes in field that we observe.

$838 \quad 6.3$ The Rate of Decay of Electric Field by Conduction

839 In a passive anvil, i.e. an anvil in which active charge separation is not occurring,

840 the electric field should decay as the charge moves downwind of the convective core.

841 Willett and Dye [2003] describe a simple model to estimate an upper limit to the decay

842 time of electric field in a passive anvil in which there is a constant influx of cosmic rays,

843 no turbulent mixing, no condensation, no evaporation or sedimentation of particles and

844 the absence of active charge separation. The mechanism for field decay in the model is

845 the bulk conduction current inside the anvil that reduces the net charge contained in its

846 interior. A modification of this simple model was used to estimate an upper limit to the

847 decay time of electric field which would be expected for the along-axis anvil penetration

848 shown in Figure 8. This case is particularly amenable to model analysis because the

849 aircraft penetration from 1850 to 1856 was oriented upwind, from the tip of the anvil

850 toward the convective core. Assuming that the anvil structure remained approximately

851 steady state (which radar observations show to be valid), both electric field and particle

852 concentration would decay while moving from the core to the anvil edge, but remain

853 essentially constant at each location along the aircraft track. In the calculations The

854 actually observed particle size distributions were used for the calculation. 
The results from the model gave a decay of electric field from 37.5 to $12 \mathrm{kV} \mathrm{m}^{-1}$

856 over a distance of $28 \mathrm{~km}$ compared to an observed decay from 37.5 to $<1 \mathrm{kV} \mathrm{m}^{-1}$ in $\sim 10$

$857 \mathrm{~km}$. Additionally the decay in the model was continuous and not nearly as rapid as the

858 observed decay and sharp decrease in field seen between 1852 and 1853 in Figure 8 . We

859 conclude that decay of electric field due to conduction currents is inadequate alone to

860 account for the abrupt changes in electric field that we observed in this or other cases.

861

8626.4 Enhancement of Electric Field in Long-Lived Anvils

863 In a separate paper Dye and Willett [2006] show that two of the long-lived ABFM

864 II anvils developed horizontally extensive regions in which the electric field, the

865 reflectivity and the particle concentrations became very uniform and maintained strength

866 over tens of minutes and tens of kilometers. They argued that charge separation occurring

867 in the melting layer might be partially responsible for the prolongation of electric field in

868 the long-lived anvils. However, because of the long time for ice particle interactions and

869 the broad particle spectrum, charge separation might also have taken place at higher

870 altitudes than the melting zone from either a non-inductive or perhaps even an inductive

871 charge separation mechanism involving ice particle collisions. Although the non-

872 inductive mechanism has been found to be most efficient when supercooled water is

873 present, the work of Jayarante et al. [1983] and others does show some charge separation

874 can occur, albeit very much smaller, even without the presence of supercooled liquid

875 water.

876 Dye and Willett [2006] also inferred that a weak updraft must have been present in 877 the two long-lived anvils. Unfortunately the wind measurements from the Citation were 
878 not reliable and often unusable, primarily because of the mass of ice particles ingested

879 into the pitot tubes.

880 The strong fields observed in the enhanced portion of the anvils seemed to be

881 associated with horizontally extensive (many $10 \mathrm{~s}$ of $\mathrm{km}$ ) regions of 20 to $25 \mathrm{dBZ}$ at $7 \mathrm{~km}$.

882 If the enhancement occurred in specific locations and not across the entire anvil, it is

883 possible that the weak fields outside the enhanced regions would reflect the values

884 expected from field decay in a passive anvil. However, when the aircraft entered the

885 enhanced parts of the anvils there might be an abrupt increase in field along the track.

886 Localized enhancement could perhaps explain the abrupt increases in field for the aircraft

887 penetrations in enhanced anvils such as 13 June 2000 and 4 June 2001. On the other

888 hand, because the particle size distributions were observed to change slowly and

889 smoothly one would think that spatial changes in the resulting ice particle collision rates

890 would also occur slowly and not lead to abrupt spatial changes in the charge structure and

891 hence electric field.

892

893 7. CONCLUDING REMARKS

894 This paper describes the ABFM II project which investigated electric fields,

895 microphysics and reflectivity in anvils, debris clouds, and regions with stratiform

896 precipitation. It has focused on the anvil measurements and presents examples for two

897 cases to illustrate the type of measurements made during ABFM II. The observations

898 have shown that electric fields in anvils often increased from weak to strong much more

899 abruptly than particle concentrations and reflectivity. 
900 In Section 6 we explored several reasons for the abrupt behavior of the electric field

901 in relationship to particle concentration, and hence reflectivity. We suggested that the

902 abrupt behavior in field observed for most of the cross anvil penetrations in passive anvils

903 might be the result of the limited area of the storm core from which charged particles

904 were being advected into the anvil. Additionally, the episodic nature of the updraft and

905 hence charge advection from the core may explain some of the along-axis anvil

906 observations. In long-lived anvils in which charge separation and subsequent

907 development had occurred, the abrupt increases in electric field might be due to localized

908 regions of charge separation, but this seems at odds with the smoothly varying particle

909 concentration. The rapid rate of decay of electric field near the anvil edge due to

910 conduction currents probably also made a contribution, but on its own, seems unlikely to

911 explain the abrupt nature of the observed field increases in the interior of the anvil.

912 Screening layers on the side of the anvil are unlikely to explain our observations. The

913 abrupt nature of the observed electric field change needs further investigation with

914 modeling studies that include explicit turbulence and mixing and detailed microphysical

915 observations as well as additional observations.

916 The composite measurements from all anvils investigated in ABFM II showed that

917 when the average reflectivity, such as in a $3-\mathrm{km}$ cube, was less than about $5 \mathrm{dBZ}$, the

918 electric field magnitude was $<3 \mathrm{kV} \mathrm{m}^{-1}$, a value that is highly unlikely to trigger lightning

919 by the Space Shuttle or a similar launch vehicle. Based on this finding, we developed the

920 Volume Averaged Height Integrated Radar Reflectivity (VAHIRR) which combines

921 radar based observations of a volume average reflectivity and the thickness of the anvil. 
922 VAHIRR is now being used to increase launch availability in new Lightning Launch

923 Commit Criteria for anvils.

The ABFM II measurements showed that the charge structure in these anvils is very

925 complicated with the vertical component of the field often changing polarity during a

926 single aircraft penetration across the anvil. Our ability to investigate and to understand

927 the charge structure was inhibited because we were rarely able to make spiral descents or

928 ascents due to restrictions by Air Traffic Control from the heavy air traffic in Florida.

929 Additional field campaigns in a location in which vertical soundings can be made would

930 be highly desirable.

931 The extensive and detailed measurements of cloud particle concentrations, types

932 and sizes; electric field and coordinated reflectivity obtained during ABFM II provide an

933 excellent data set with which to investigate a number of physical processes in anvils,

934 debris clouds and stratiform regions of Florida thunderstorms. Possible topics include:

935 the charge separation mechanisms and related particle interactions apparently occurring

936 near the melting zone and at higher altitudes in long-lived anvils; changes in particle type

937 (especially riming) during penetrations across an anvil; examination of the charge

938 structure in anvils; the evolution of the particle size distribution by aggregation and

939. sedimentation in both high and weak electric field situations; and the kinematic

940 mechanisms responsible for the updraft and hence enhancement of reflectivity in long-

941 lived anvils. We hope that other investigators might pursue these and/or other topics

942 using the ABFM II data set. Interested investigators may contact Frank Merceret at the

943 Kennedy Space Center Weather Office (francis.j.merceret@nasa.gov) for access to the 944 data. 
946 We gratefully acknowledge financial support from the National Aeronautics and

947 Space Administration and the National Reconnaissance Office, as well as the advocacy

948 and administrative support of John Madura of the Kennedy Space Center Weather Office.

949 In addition, we would like to acknowledge flight support from. Mike Poellot and the

950 Citation pilots and ground crews; weather support from the 45th Weather Squadron; and

951 ground support from the 45th Space Wing and NASA Kennedy Space Center. We

952 particularly wish to recognize Dr. Harry C. Koons for his extremum analysis of the

953 ABFM II anvil data set and for his thorough and careful contributions. Don

954 MacGorman's comments helped improved the manuscript. The National Center for

955 Atmospheric Research is partially supported by the National Science Foundation.

956 
957

958 Bailey, M. and J. Hallett 2002, Nucleation effects on the habit of vapour grown ice

959 crystals from $-18{ }^{\circ} \mathrm{C}$ To $-42{ }^{\circ} \mathrm{C}$, Q. J. Royal. Met. Soc., 128, 1461-1484.

960

961 M.G. Bateman, D.M. Mach, S. Lewis, J.E. Dye, E. Defer, C.A. Grainger, P.T. Willis, F.J.

962 Merceret, D. Boccippio, and H.J. Christian, 2005, Comparison of in-situ electric field and

963 radar derived parameters for stratiform clouds in Central Florida, Conf. on Meteorol.

964 Apps. of Lightning Data, AMS Annual Meeting, San Diego, Jan. 23-28, Paper No. P1.10.

965

966 Bateman, M.G., M.F. Stewart, R.J. Blakeslee, S.J. Podgorny, H.J. Christian, D.M. Mach,

967 J.C. Bailey, D. Daskar and A.K. Blair, 2006, A low noise, computer-controlled, internally

968 digitizing rotating-vane electric field mill for airborne platforms, accepted for publication

969 in J. Atmos. Ocean. Tech.

970

971 Blakeslee, R.J., H.J. Christian, and B. Vonnegut, 1989, Electrical measurements over

972 thunderstorms, J. Geophys. Res., 94, 135-140.

973

974 Boccippio, D.J., S. Heckman, and S.J. Goodman, 2000a, A diagnostic analysis of the

975 Kennedy Space Center LDAR network: 1. Data Characteristics, J. Geophys. Res., 106, $976 \quad 4787-4796$.

977 
978 Boccippio, D.J., S. Heckman, and S.J. Goodman, 2000b, A diagnostic analysis of the

979 Kennedy Space Center LDAR network: 2. Cross sensor studies, J. Geophys. Res., 106, $980 \quad 4769-4786$.

981

982 Boyd, B.F., W.P. Roeder, D.L. Hajek, M.B. Wilson, 2005, Installation, upgrade and 983 evaluation of a short baseline cloud-to-ground lightning surveillance system used to 984 support space launch operations, Conf. on Meteorol. Applic. of Lightning Data, Amer.

985 Meteorol. Soc. Annual Meeting, San Diego CA, Jan. 9 - 13, 986

987 Byrne, G.J., A.A. Few, and M.F. Stewart, 1989, Electric field measurements within a 988 severe thunderstorm anvil, J. Geophys. Res., 94, 6297-6307.

989

990 Cummins, K. L., M. J. Murphy, E. A. Bardo, W. L. Hiscox, R. B. Pyle, and A. E. Pifer, 991 1998, A combined TOA/MDF technology upgrade of the U.S. National Lightning 992 Detection Network, J. Geophys. Res., 103, 9035- 9044.

993

994 Dye, J. E., J. J. Jones, W. P. Winn, T. A. Cerni, B. Gardiner, D. Lamb, R. L. Pitter, J.

995 Hallett, and C. P. R. Saunders, 1986, Early electrification and precipitation development

996 in a small, isolated Montana cumulonimbus, J. Geophys. Res., 91, $1231-1247$. 997

998 Dye, J.E., S. Lewis, M.G. Bateman, D.M. Mach, F.J. Merceret, J.G. Ward and C.A.

999 Grainger, 2004, Final Report on the Airborne Field Mill Project (ABFM) 2000-2001

1000 Field Campaign, NASA/TM-2004-21 1534, National Aeronautics and Space 
1001 Administration, Kennedy Space Center, FL, $132 \mathrm{pp}$. Available from NASA Center for

1002 AeroSpace Information (CASI), 7121 Standard Drive, Hanover, MD 21076-1320.

1003

1004 Dye, J.E. and J.C.Willett, 2006, The enhancement of reflectivity and electric field in 1005 long-live Florida anvils. Submitted to Month. Weath. Rev, Aug.31, 2006.

1006

1007 Field, P.R., Wood, R., Brown, P.R.A., Kaye, P.H., Hirst, E., Greenaway, R., Smith, J.A., 1008 2003, Ice particle interarrival times measured with a fast FSSP, J. Atmos. Ocean Tech., $100920,249-261$.

1010

1011 Field P.R., Heymsfield A.J. Bansemer A., 2006, Shattering and particle interarrival times 1012 measured by optical array probes in ice clouds. J. Atmos. Ocean Tech.,23,. in press.

1013

1014 Heymsfield, A.J., and L.M. Milosevich, 1989, Evaluation of liquid water measuring

1015 instruments during FIRE, J. Atmos. Ocean. Tech., 6, 378-388.

1016

1017 Jayaratne, E.R., C.P.R. Saunders, and J. Hallett, 1983: Laboratory studies of the charging 1018 of soft-hail during ice crystal interactions. Quart. J. R. Meteor. Soc., 109, 609-630.

1019

1020 Klett, J.D., 1972, Charge screening layers around electrified clouds, J. Geophys. Res., 77, $1021 \quad 3187-3195$.

1022 
1023 Krider, E.P., H.C. Koons, R.L. Walterschied, W.D. Rust, and J.C. Willett, 1999, Natural

1024 and triggered lightning launch commit criteria (LCC), Aerospace Report No. TR-

1025 99(1413)-1, The Aerospace Corporation, El Segundo, CA, 15 pp.

1026

1027 Lawson, P.R., B.A. Baker, C.G. Schmitt, T.L. Jensen, 2001. An overview of

1028 microphysical properties of Arctic clouds observed in May and July 1998 during FIRE

1029 ACE, J. Geophys. Res., 106, 14989-15014.

1030

1031 Lawson, R. P., R. E. Stewart and L. J. Angus, 1998, Observations and numerical

1032 simulations of the origin and development of very large snowflakes, J. Atmos. Sciences,

$1033 \mathbf{5 5}, 3209-3229$.

1034

1035 Lennon, C and L.S. Maier, 1991, Lightning mapping system, Proc. Internat. Aerosp. and

1036 Grnd Conf. On Lightning and Static Electr., Cocoa Beach, FL, Apr. 16-19, 1991, 89-91.

1037

1038 MacGorman, D. R., and W. D. Rust, 1998, The Electrical Nature of Storms, Oxford

1039 Univ. Press, New York, 422 pp.

1040

1041 Mach, D. M.and W. J. Koshak, 2003, General matrix inversion technique for the

1042 calibration of electric field sensor arrays on aircraft platforms, Proc. $12^{\text {th }}$ Internat. Conf.

1043 on Atmosph. Electr., Versailles, France, 9-13 June, 207-210. 
1045 Maier, M.W., 1991, Evaluation of 1990 bias error corrections for the ESMC cloud-to-

1046 ground lightning surveillance system, CSR-322-003, Eastern Space and Missile Center

1047 Report under Contract F08606-88-C-0014, Computer Sciences, Raytheon Corporation.

1048

1049 Marshall, T.C., W.D. Rust, and W.P. Winn, 1984, Screening layers at the surface of

1050 thunderstorm anvils, Proc. VII Intern. Conf. on Atmosph. Electr., Albany, NY, June 3-8,

1051 pp.346-347.

1052

1053 Merceret, F.J., J.G. Ward, D.M. Mach, M.G. Bateman and J.E. Dye, 2006, On the

1054 magnitude of the electric field near thunderstorm-associated clouds, to be submitted to J.

1055 Appl. Meteorol.

1056

1057 Mohr, C.G., L.J. Miller, R.L. Vaughan, and H.W. Frank, 1986, The merger of mesoscale

1058 data sets into a common Cartesian format for efficient and systematic analysis, J. Atmos.

1059 Oceanic Tech., 3, 143-161.

1060

1061 Office of the Federal Coordinator for Meteorology (OFCM), 2003, Federal

1062 Meteorological Handbook No. 11: Doppler Radar Observations, part A, 34 pp.

1063

1064 Reiss, R.-D., and M. Thomas, 2001, Statistical Analysis of Extreme Values, $2^{\text {nd }}$ Edition,

1065 Birkhauser Verlag, Boston, 443 pp.

1066 
1067 Schild, J.J., 2003, Liquid water in thunderstorm anvils over Kennedy Space Center, 1068 Florida during the summer 2001 ABFM field campaign, M.S. Thesis, Univ. of North 1069 Dakota, 55pp.

1070

1071 Strapp, J.W., F. Albers, A. Reuter, A.V. Korolev, U. Maixner, E. Rashke, and Z.

1072 Vukovic, 2001, Laboratory measurements of the response of a PMS OAP-2DC, J. Atmos

1073 Ocean. Tech, 18, 1150-1170.

1074

1075 Vonnegut, B., C.B. Moore, R.P.Espinola, and H.H.Blau Jr., 1966, Electric potential

1076 gradients above thunderstorms, J. Atmos. Sci., 23, 764-770.

1077

1078 Ward, J.L., F.J. Merceret and C.A. Grainger, 2003, An automated cloud-edge detection

1079 algorithm using cloud physics and radar data, NASA Technical Memorandum

1080 NASA/TM-2003-211189, June 2003, 20 pp.

1081

1082 Wheeler, M.W., 1997, Report on the Radar/PIREP Cloud Top Discrepancy Study, NASA

1083 Kennedy Space Center FL, Contractor Report CR-204381, 18 pp.

1084

1085 Willett, J.C., D.A. Davis, and P. Laroche, 1999, An experimental study of positive

1086 leaders initiating rocket-triggered lightning, Atmospheric Research, 51, 189-219. 
1088 Willett, J.C. and J.E. Dye, 2003, A simple model to estimate electrical decay times in

1089 anvils, Proc. $12^{\text {th }}$ Intern. Conf. on Atmosph. Electr., Versailles, France, June 2003, 267.

1090271.

1091

1092 Winn, W.P., C.B. Moore, C.R. Holmes, and L.G. Byerley, 1978, Thunderstorm on July

1093 16, 1975 over Langmuir Laboratory: A case study, J. Geophys. Res., 83, 3079-3092. 